\title{
p53-Regulated Long Noncoding RNA PRECSIT Promotes Progression of Cutaneous Squamous Cell Carcinoma via STAT3 Signaling
}

Minna Piipponen, ${ }^{* \dagger \ddagger}$ Liisa Nissinen, ${ }^{* \dagger \ddagger}$ Pilvi Riihilä, ${ }^{* \dagger \ddagger}$ Mehdi Farshchian, ${ }^{* \ddagger}$ Markku Kallajoki, ${ }^{\S}$ Juha Peltonen, Sirkku Peltonen, ${ }^{*}$ and Veli-Matti Kähäri ${ }^{* \dagger}$

From the Department of Dermatology* and the Cancer Research Laboratory, ${ }^{\dagger}$ Western Cancer Centre of the Cancer Center Finland (FICAN West), and the Department of Pathology, ${ }^{\S}$ University of Turku and Turku University Hospital, Turku; the MediCity Research Laboratory and the Department of Cell Biology and Anatomy, "University of Turku, Turku, Finland

Accepted for publication October 15, 2019.

Address correspondence to Veli-Matti Kähäri, M.D., Ph.D., Department of Dermatology, University of Turku and Turku University Hospital, Hämeentie 11 TE6, FI-20520 Turku, Finland. Email: veli-matti.kahari@utu.fi.
Long noncoding RNAs (IncRNAs) have emerged as putative biomarkers and therapeutic targets in cancer. The role of IncRNA LINC00346 in cutaneous squamous carcinoma (CSCC) was examined. The expression of LINC00346 was up-regulated in CSCC cells compared with normal human epidermal keratinocytes. Elevated expression of LINC00346 was noted in tumor cells in CSCC tissue sections in vivo, as compared with CSCC in situ, and actinic keratosis by RNA in situ hybridization; and the expression in seborrheic keratosis and normal skin was very low. Immunohistochemical analysis of cSCC tissue sections and functional assays of cSCC cells in culture showed that LINC00346 expression is down-regulated by p53. Knockdown of LINCO0346 inhibited invasion of CSCC cells in culture and suppressed growth of human CSCC xenografts in vivo. Knockdown of LINC00346 inhibited expression of activated STAT3 and resulted in down-regulation of the expression of matrix metalloproteinase (MMP)-1, MMP-3, MMP-10, and MMP-13. Based on these observations LINC00346 was named p53 regulated carcinoma-associated STAT3-activating long intergenic non-protein coding transcript (PRECSIT). These results identify PRECSIT as a new p53-regulated IncRNA, which promotes progression of CSCC via STAT3 signaling. (Am J Pathol 2020, 190: 503-517; https://doi.org/10.1016/j.ajpath.2019.10.019)
Non-protein coding RNAs have emerged as functionally important mediators in cell regulation, for example, during tissue development and differentiation, as well as in different pathological conditions. ${ }^{1}$ Long noncoding RNAs (IncRNAs) present a widely uncharacterized group of single-stranded RNA transcripts longer than 200 nucleotides, which interact with DNA, RNA, or proteins, making them versatile regulators in all cellular compartments. ${ }^{2}$ lncRNAs represent an important level of cell regulation, especially due to their temporal and tissue-specific expression at different stages of tissue development, homeostasis, repair, or stress response. ${ }^{3}$ Several lncRNAs have been implicated in cancer, and specific lncRNAs exert either tumor suppressive or tumor promoting functions. ${ }^{4}$ IncRNAs are generally stable in body fluids and tissues, and their differential expression in cancer makes them attractive biomarkers and putative therapeutic targets in cancer. ${ }^{5}$
Keratinocyte-derived cutaneous squamous cell carcinoma (cSCC) is the most common metastatic skin cancer globally. ${ }^{6,7}$ Although the majority of cSCCs arise in the sundamaged skin, other important risk factors for cSCC include immunosuppression and chronic ulcers. ${ }^{8,9}$ Tumor protein 53 (TP53) gene is usually mutated early in

\footnotetext{
Supported by the Finnish Cancer Research Foundation, the Cancer Society of South-West Finland, the Jane and Aatos Erkko Foundation, the Sigrid Jusélius Foundation, the state research funding of the Turku University Hospital grant 13336; and by grants from Kymenlaakso Regional Fund of the Finnish Cultural Foundation (M.P.), Ida Montin Foundation (M.P.), Instrumentarium Science Foundation (M.P.), the Paulo Foundation (M.P.), the Maud Kuistila Memorial Foundation (M.P.), University of Turku Graduate School Funding, and Turku University Foundation (M.P.). Disclosures: None declared.

Portions of this work were presented at the 49th Annual ESDR Meeting held September 9, 2019, in Bordeaux, France, and published in Morressier.
} 
keratinocyte carcinogenesis in cSCC development, followed by marked accumulation of UV-induced simple mutations. ${ }^{10-12}$ Other commonly mutated genes in cSCC include NOTCH1, HRAS, and CDKN2A. ${ }^{10,13}$ Currently, there is a need for clinically useful biomarkers for predicting the risk of recurrence and metastasis of primary cSCC. Many potential markers have been identified, including inflammation-related complement system proteins, ${ }^{14-16} \mathrm{PD}$ L1, ${ }^{17}$ Serpin A1, ${ }^{18}$ EphB2, ${ }^{19}$ AIM2, ${ }^{20}$ and P300/CBPassociated factor (PCAF). ${ }^{21}$ The authors have previously elucidated the mechanistic role of lncRNA PICSAR (p38 inhibited cutaneous squamous cell carcinoma associated lincRNA) in cSCC. ${ }^{22,23}$ PICSAR promotes $\mathrm{CSCC}$ growth by increasing activity of ERK1/2 via down-regulation of the expression of DUSP6. ${ }^{22}$ In addition, PICSAR decreases adhesion and promotes migration of cSCC cells by downregulating $\alpha 2 \beta 1$ and $\alpha 5 \beta 1$ integrin expression, ${ }^{23}$ However, the role of lncRNAs in cSCC is still largely unknown.

In this study, the authors show that lncRNA LINCO0346 is specifically overexpressed by cSCC cells in culture and in vivo, and that LINC00346 is regulated by p53. The authors demonstrate that LINCO0346 regulates the expression and activity of STAT3, which in turn up-regulates the expression of matrix metalloproteinases (MMPs) MMP-1, MMP-3, MMP-10, and MMP-13 and promotes invasion of cSCC cells. On the basis of these observations, and with the approval of HUGO Gene Nomenclature Committee, LINC00346 was named p53 regulated carcinoma-associated STAT3 activating long intergenic non-protein coding transcript (PRECSIT). Together, these results identify PRECSIT as a p53-regulated lncRNA, which promotes progression of cSCC via STAT3 signaling.

\section{Materials and Methods}

\section{Ethical Issues}

The use of tumor and normal skin (NS) samples was approved by the Ethics Committee of the Hospital District of Southwest Finland. All participants gave their written informed consent, and the study was performed with the permission of Turku University Hospital, according to the Declaration of Helsinki. The experiments with mice were performed with the permission of the State Provincial Office of Southern Finland.

\section{Cell Cultures}

All cSCC cell lines were established from surgically removed cSCCs in Turku University Hospital. ${ }^{18}$ Normal human epidermal keratinocytes (NHEKs) were established from the skin of healthy individuals undergoing mammoplasty, ${ }^{18}$ and NHEK-PC was purchased from PromoCell (Heidelberg, Germany). The spontaneously immortalized human keratinocyte line ( $\mathrm{HaCaT}$ ) was kindly provided by Dr. Norbert E. Fusenig (The German Cancer Research
Center, Heidelberg, Germany). NHEKs, HaCaT, and cSCC cells were cultured as previously described. ${ }^{14}$ The authenticity of all cSCC cell lines has been verified by short tandem repeat profiling. ${ }^{24}$ To determine the p53 mutational status in NHEKs and cSCC cells, TP53 single-nucleotide variants were examined by using the Integrative Genomics Viewer software version $2.3^{25}$ ) in the RNA sequencing (RNA-seq) data of cSCC cells ${ }^{19}$ (https://www.ncbi.nlm.nih. gov/geo; accession number GSE66412) (Supplemental Figure S1 and Supplemental Table S1).

\section{Real-Time Quantitative PCR}

Total RNA was extracted from cultured cSCC cells and NHEKs using RNeasy mini kit (Qiagen, Germantown, MD). For cytoplasmic fractions, cSCC cells were washed with ice-cold phosphate-buffered saline and lyzed in $0.1 \%$ NP40 in phosphate-buffered saline with protease inhibitor cocktail (cOmplete ULTRA Tablets; Roche, Basel, Switzerland) and ribonuclease inhibitor (RNasin, $50 \mathrm{U} / \mathrm{mL}$; Promega, Madison, WI). Cell lysate was centrifuged, and the supernatant was collected as cytoplasmic fraction. The remaining pellet was collected as nuclear fraction. Complementary DNA was synthesized from RNA extracted from whole-cell lysates or cytoplasmic and nuclear fractions, and used for real-time quantitative PCR (qPCR) analysis. Specific primers and probe for PRECSIT were designed with RealTimeDesign Software (https://www.biosearchtech.com, last accessed April 17, 2012; LGC Biosearch Technologies, Teddington, UK) and purchased from Oligomer (Helsinki, Finland) (Table 1). Primers and probe for $M M P 3$ and nuclear-retained lncRNA MALAT1 were purchased from Thermo Fisher Scientific (Waltham, MA; catalog numbers Hs00968305_m1, Hs00273907_s1). Primers and probes for $M M P 1, M M P 10$, and MMP13 (Table 1) were designed as previously described. ${ }^{26}$ All qPCR reactions were performed using the QuantStudio 12K Flex (Thermo Fisher Scientific) system at the Finnish Functional Genomics Centre in Turku, Finland. ACTB ( $\beta$-actin) mRNA was used as reference (Table 1). Samples were analyzed using the standard curve method in three parallel reactions with threshold cycle values $<5 \%$ of the mean threshold cycle.

\section{Tissue Samples and Immunohistochemical Analysis}

Tissue microarrays consisting of samples from normal sunprotected skin $(n=10)$, seborrheic keratosis (SK; $n=26$ ), actinic keratosis (AK; $n=50)$, cSCC in situ $(n=25)$, and invasive cSCC $(n=81)$ were generated from the archival paraffin blocks from the Department of Pathology, Turku University Hospital. ${ }^{15,19}$ Sections were stained with mouse monoclonal p53 antibody (DO-7, dilution 1:100; SigmaAldrich, St. Louis, MO) at the Histology Core of the Institute of Biomedicine at the University of Turku, Turku, Finland, and visualized using the Pannoramic Midi FL slide scanner (3DHISTECH Ltd., Budapest, Hungary). 
Table 1 List of Specific Primers and Probes for Real-Time Quantitative PCR

\begin{tabular}{|c|c|c|}
\hline Gene/RNA & Sequence & \\
\hline \multirow[t]{2}{*}{ PRECSIT } & Forward & 5'-CGAGGGTTGAACATTGTTGTGAC-3' \\
\hline & Reverse & $5^{\prime}-\mathrm{CCACAGCTCCACCACTAGAC-3^{ \prime }}$ \\
\hline \multirow[t]{3}{*}{$M M P 1$} & Forward & 5'-AAGATGAAACGTGGACCAACAATT-3' \\
\hline & Reverse & $5^{\prime}-$ CCAAGAGAATGGAAGAGTTC-3' \\
\hline & Probe & 5'-FAM-CAGAGAGTACAACTTACATCGTGTTGCGGCTC-TAMRA-3' \\
\hline MMP10 & Probe & 5'-FAM-CATCAGGCACCAATTTATTCCTCGTTGCT-TAMRA-3' \\
\hline \multirow[t]{3}{*}{ MMP13 } & Forward & 5'-AAATTATGGAGGAGATGCCCATT-3' \\
\hline & Reverse & 5'-TCCTTGGAGTGGTCAAGACCTAA-3' \\
\hline & Probe & 5'-FAM-CTACAACTTGTTTCTTGTTGCTGCGCATGA-TAMRA-3' \\
\hline ACTB & Forward & $5^{\prime}-\mathrm{TCACCCACACTGTGCCCATCTACGC-3^{ \prime }}$ \\
\hline
\end{tabular}

ACTB, ß-actin; MMP1, matrix metallopeptidase 1; MMP10, matrix metallopeptidase 10; MMP13, matrix metallopeptidase 13; PRECSIT, p53 regulated carcinoma-associated STAT3-activating long intergenic non-protein coding transcript.

\section{RNA in Situ Hybridization}

Formalin-fixed, paraffin-embedded tissue samples were subjected to RNA in situ hybridization (RNA-ISH) analysis using RNAscope ISH Assay (Advanced Cell Diagnostics, Newark, CA) by Bioneer A/S (Hørsholm, Denmark). The assay was performed by using automated Ventana Discovery Ultra slide-staining system (Roche) as previously described. ${ }^{27}$ PRECSIT-specific probe (catalog number 559389) was designed and purchased at Advanced Cell Diagnostics (ACD, Newark, CA). Specific probes for human PPIB (Cyclophilin B) and bacterial DapB (4hydroxy-tetrahydrodipicolinate reductase) mRNAs were used as positive and negative controls, respectively (both from ACD). PRECSIT expression was visualized using the Pannoramic Midi FL slide scanner (3DHISTECH Ltd.). PRECSIT expression was quantitated in the epidermis or tumor cells by counting the visibly detectable PRECSIT particles localized to the nucleus. Additionally, PRECSIT expressing cells were grouped into cells detected with five or more and fewer than five PRECSIT particles per cell. To evaluate PRECSIT expression level in a tissue section, the number of PRECSIT-positive cells was compared with the number of total cell count in a section at $\times 40$ magnification using QuPath bioimage analysis software version 0.1.2. ${ }^{28}$

\section{Adenoviral Infection}

UT-SCC7, UT-SCC12A, and HaCaT cells were infected with recombinant adenovirus RAdp53 containing the gene for human wild-type p53 ${ }^{29}$ (kindly provided by Dr. Prem Seth, Des Moines University, Des Moines, IA) or with empty adenovirus RAd66 ${ }^{30}$ (kindly provided by Dr. Gavin W.J. Wilkinson, University of Cardiff, Wales), and cells were incubated for 6 hours in $0.5 \%$ fetal calf serum at a multiplicity of infection of 600 . Cell lysates were collected
24 and 48 hours after infection and analyzed by qPCR and Western blot. For determination of cell viability, cells were plated on a 96-well plate 24 hours after infection, and the number of viable cells was determined using a Cell Counting kit-8 (Dojindo Laboratories, Kumamoto, Japan). Absorbance was measured at $450 \mathrm{~nm}$ (Multiskan FC microplate reader; Thermo Scientific, Vantaa, Finland).

\section{Western Blot Analysis}

Cell lysates from adenovirally infected (RAd66 and RAdp53) UT-SCC7 and UT-SCC59A cells were analyzed with antibodies specific for p53 (DO-1; Santa Cruz Biotechnology, Santa Cruz, CA) and p21 (2G12; BD Biosciences, San Jose, CA). Lysates of LINC00346 and control siRNA transfected cultures were analyzed with antibodies specific for phosphorylated STAT3 (pSTAT3, D3A7) and total STAT3 (124H6; both from Cell Signaling Technology, Beverly, MA). $\beta$-Actin (A1978; Sigma-Aldrich) expression level was used as loading control. Matrix metalloproteinase levels in serum-free medium were determined by Western blot analysis 72 hours after transfection using antibodies specific for MMP-1 (411E5; Merck Millipore, Temecula, CA), MMP-3 (HPA007875; Sigma-Aldrich), MMP-10 (IVC5; Thermo Fisher Scientific), and MMP-13 (Ab-3; Merck Millipore). Expression of tissue inhibitor of matrix metalloproteinases 1, TIMP-1 (Ab-1; Merck Millipore), was used as a sample control for MMPs. Protein expression was quantitated using fluorescently labeled secondary antibodies (LI-COR Biosciences, Lincoln, NE) and the LI-COR Odyssey CLx fluorescent imaging system (LI-COR Biosciences).

\section{RNA Sequencing}

RNA was isolated from PRECSIT siRNA1- and control siRNA-treated cSCC cell lines $(n=3$; UT-SCC7, 
UT-SCC59A, and UT-SCC105) 72 hours after transfection using miRNeasy Mini Kit (Qiagen), and the RNA-seq analysis was performed using Illumina HiSeq3000 system (Illumina, San Diego, CA) at the Finnish Functional Genomics Centre, Turku. The reads were aligned against the human reference genome (hg38), and the TMM (trimmed mean of M values) normalization method was used for data normalization $(\mathrm{R}$ version 3.3/Bioconductor package edge $\mathrm{R}$ version $3.3^{31}$ ). Limma package version $3.10^{32}$ and $t$-test was used for statistical analysis of the mean expression values between control siRNA and PRECSIT siRNA1-treated cSCC cell lines. The top 40 most up- and down-regulated genes are shown in Supplemental Tables S2 and S3. Morpheus software (https://software.broadinstitute.org/morpheus, last accessed January 26, 2018) was used for gene expression visualization and to generate heatmaps. RNA-seq data were further analyzed using the Gene Ontology Enrichment Analysis (Gene Ontology, http://www. geneontology.org, last accessed October 31, 2018), Kyoto Encyclopedia of Genes and Genomes Pathway Analysis (KEGG, http://www. genome.jp/kegg, last accessed October 31, 2018), and the Reactome Pathway Knowledgebase (https://reactome.org; last accessed October 31, 2018). RNA-seq data of PRECSIT knockdown cSCC cells are available online at the Gene Expression Omnibus (https://www.ncbi.nlm.nih. gov/geo; accession number GSE138232). The GeneHancer database of genome-wide enhancer-to-gene associations ${ }^{33}$ was used to examine transcription factor binding sites in PRECSIT gene promoter.

\section{Knockdown of PRECSIT and Functional Studies in Culture}

cSCC cells were cultured to $50 \%$ confluence and transfected with negative control siRNA (AllStars Negative Control siRNA; Qiagen) or following commercially available siRNAs (75 nmol/L) targeting PRECSIT: Hs_C13orf29_2 (PRECSIT siRNA1) (target sequence 5'-GAGGTTCGGGAAGGAAAGGAAA-3'); Hs_C13orf29_4 (PRECSIT siRNA2) (target sequence 5'-CAGGGATGGTGACAAGCGGAA- $3^{\prime}$ ); Hs_C13orf29_1 (PRECSIT siRNA3) (target sequence 5' TAAGACATGAATAATAGTAGA-3'). Cell lysates were collected 72 hours after transfection for Western blot and qPCR analysis, and the cell culture medium was collected for detection of MMP levels by Western blot analysis.

To study cell invasion, cSCC cells were plated on a collagen type I-coated $\left(5 \mu \mathrm{g} / \mathrm{cm}^{2}\right.$, PureCol; Advanced BioMatrix, San Diego, CA) ImageLock 96-well plate (Essen Bioscience, Ann Arbor, MI) 24 hours after transfection with PRECSIT siRNAs or negative control siRNA, and cells were allowed to adhere overnight. For studying cell invasion after STAT3 inhibition, cSCC cells were plated on collagen I and treated with S31-201 (100 $\mu \mathrm{mol} / \mathrm{L}$; Cayman Chemical, Ann Arbor, MI) 24 hours prior to wounding. Cell monolayer was scratched and collagen type I solution was added by mixing type I collagen (PureCol) with $5 \times$ Dulbecco's Modified Eagle Medium and $0.2 \mathrm{~mol} / \mathrm{L}$ HEPES buffer ( $\mathrm{pH} 7.4)$ at a ratio of 7:2:1, respectively. Finally, $1 \mathrm{~mol} / \mathrm{L} \mathrm{NaOH}$ was added to obtain a final $\mathrm{pH}$ of 7.4. Cell culture medium with $0.5 \%$ fetal calf serum was added after letting the collagen type I solution $(2.2 \mathrm{mg} / \mathrm{mL})$ polymerize for 2 hours at $37^{\circ} \mathrm{C}$. For STAT3-inhibited cSCC cells, S31-201 was added to the culture medium, and fresh medium with S31-201 was changed the next day. The gap closure was imaged using the IncuCyte ZOOM real-time cell imaging system (Essen Bioscience), and the relative cell invasion was quantitated using the IncuCyte ZOOM software version 2016B (Essen Bioscience).

To determine the effect of PRECSIT on cell proliferation, cSCC cells (UT-SCC7 or UT-SCC59A) were transfected with negative control siRNA or three different siRNAs targeting PRECSIT. Transfected cells were plated in a 96-well plate 24 hours after transfection and imaged using the IncuCyte ZOOM real-time cell imaging system (Essen Bioscience). Quantitation of the cell confluence was measured using the IncuCyte ZOOM software. After 24 hours of PRECSIT siRNA transfection, cSCC cells were plated on a 96-well plate, and the number of viable cells was determined using a Cell Counting kit-8 (Dojindo Laboratories).

\section{Human CSCC Xenografts}

cSCC cells (UT-SCC7) were transfected with PRECSIT siRNA1 or control siRNA and incubated for 72 hours. Transfected cells $\left(5 \times 10^{6}\right)$ were injected subcutaneously in $100 \mu \mathrm{L}$ of phosphate-buffered saline into the backs of 6week-old female SCID (severe combined immunodeficient) mice (CB17/Icr-Prkdcscid/IcrIcoCrl) (Charles River Laboratories, Wilmington, MA) (control siRNA, $n=6$, PRECSIT siRNA1, $n=8$ ). Tumor size was measured twice a week, and the volume of tumors was calculated as ${ }^{34}$ :

$$
\mathrm{V}=\left(\text { length } \times \text { width }^{2}\right) / 2
$$

Mice were sacrificed 16 days after tumor implantation, and tumors were excised and embedded in paraffin. For histologic analysis, tumors were stained with hematoxylin and eosin. To examine localization of active STAT3, tumor sections were stained with phosphorylated STAT3 antibody (pSTAT3, D3A7; Cell Signaling Technology) with Mayer's hematoxylin (Sigma-Aldrich) as a counterstain.

\section{Statistical Analysis}

Statistical analyses were performed using SPSS Statistics software for Windows, version 25 (IBM, Armonk, NY). The sample size was determined to be adequate for statistical analysis of the data. To determine the significance of differences between two sample groups, two-tailed $t$-test or $U$-test was used. Fisher exact test was used for statistical comparisons of the immunohistochemistry and RNA-ISH of tissue samples. Linear regression test was used to analyze the correlation between the percentage of PRECSIT-positive cells and PRECSIT 
accumulation in tissue sections. Spearman correlation test was used to compare the percentage of PRECSIT-positive cells and p53 immunoreactivity.

\section{Results}

\section{PRECSIT Is Up-Regulated in cSCC Cells}

The authors have previously observed that several lncRNAs are differentially expressed in cSCC cells compared with NHEKs. ${ }^{22}$ PRECSIT (LINC00346) was identified as one of the most up-regulated lncRNAs in cSCC cells with very low expression in NHEKs based on RNA-seq. ${ }^{22}$ Here, a significant up-regulation of PRECSIT was detected in cSCC cell lines $(n=7)$ compared with NHEKs $(n=6)$ by qPCR (Figure 1A). PRECSIT was detected both in the cytoplasm and nucleus of cSCC cells, but it was enriched in the nuclear fraction by qPCR analysis (Figure 1B). MALAT1 and ACTB ( $\beta$-actin) mRNA levels were determined as controls for nuclear $^{35}$ and cytoplasmic localization, respectively (Figure 1B).

\section{Expression of PRECSIT Is Up-Regulated in Invasive cSCC, cSCC in Situ, and Actinic Keratosis in Vivo}

Expression of PRECSIT in vivo was analyzed in paraffinembedded tissue sections of NS $(n=10)$, benign epidermal papilloma, SK $(n=26), \mathrm{AK}(n=50), \operatorname{cSCC}$ in situ (cSCCIS; $n=25)$, and invasive $\operatorname{cSCC}(n=81)$ with RNA-ISH (Figure 1, C-G). Primarily nuclear localization was noted for PRECSIT in tissue samples (Figure 1, C-G). The percentage of PRECSIT-positive cells was significantly higher in invasive cSCC than in NS, SK, and noninvasive cSCC precursor lesions (AK and cSCCIS) (Figure 1H). Expression of PRECSIT was also higher in AK and cSCCIS when compared with SK lesions (Figure 1H). Nearly half $(49 \%)$ of the invasive cSCCs showed strong $(+++)$ PRECSIT expression ( $>30 \%$ PRECSIT-positive cells), whereas mostly weak $(+)(<15 \%$ PRECSIT-positive cells) or moderate $(++)(15 \%$ to $30 \%$ PRECSIT-positive cells) expression was noted in NS and SK (Figure 1I). PRECSIT copy number per cell was quantitated by counting the number of nuclear PRECSIT particles in tumor cells (cSCC, cSCCIS, AK, SK) and keratinocytes (NS) in microscopic images. A significantly higher percentage of tumor cells with a high level of PRECSIT expression (five or more particles per cell) was detected in invasive cSCC (Figure 1J), as compared with NS, SK, or noninvasive malignant lesions AK and cSCCIS (Figure $1 \mathrm{~J}$ ). In addition, the relative number of tumor cells detected with five or more PRECSIT particles correlated with the overall percentage of PRECSIT-positive cells in tissue sections of AK, cSCCIS, and invasive cSCC (Supplemental Figure S2). Human PPIB (Cyclophilin B) and bacterial $D a p B$ (4-hydroxy-tetrahydrodipicolinate reductase) mRNAs were used as positive and negative controls, respectively, for RNA-ISH (Supplemental Figure S3).
Accumulation of PRECSIT Is Associated with the Absence of p53 Expression in Vivo

Elevated expression of PRECSIT noted in UV-induced malignant lesions AK, cSCCIS, and invasive cSCC compared with NS and SK suggested an association between p53 mutation and PRECSIT expression. The expression of p53 in vivo was examined by immunohistochemistry using an antibody that recognizes both the wildtype and mutated p53. Based on the p53 staining intensity, the tissues were categorized in four groups: weak $(+)$, moderate $(++)$, strong $(+++)$, and negative (-) (Figure 2A and Supplemental Table S2). All NS lesions showed weak nuclear staining in the basal epidermal keratinocytes (Figure 2, A and B). By contrast, 52\% of the AK and cSCCIS, and $67 \%$ of cSCC lesions displayed strong or moderate nuclear accumulation of p53 (Figure 2, A and B). A subset of the AK, cSCCIS (8\%), and cSCC (11\%) lesions were negative for p53 (Figure 2, A and B). Most SK tissue sections showed weak p53 expression similar to NS (Figure 2B). Strong or negative staining for p53 was only detected in malignant tissue sections $\mathrm{AK}$, cSCCIS, and cSCC (Figure 2, A and B).

Comparison of p53 level to PRECSIT expression in parallel tissue sections revealed a high level of PRECSIT expression ( $>30 \%$ PRECSIT-positive cells) in AK, cSCCIS, and cSCC tissues within all p53 staining groups (weak, moderate, strong, and negative), but there was no correlation between the relative number of PRECSITpositive cells and p53 staining intensity (Figure 2C). All NS samples with weak p53 staining showed also weak $(<15 \%$ PRECSIT-positive cells) or moderate $(15 \%$ to $30 \%$ PRECSIT-positive cells) PRECSIT expression (Figure 2C). Similarly, most of the SK sections with weak or moderate p53 staining showed weak or moderate PRECSIT expression (Figure 2C). However, 56\% of all cSCC tissue sections showed PRECSIT accumulation (five or more PRECSIT particles per cell) and the majority of these tissue sections (45\%) showed negative p53 immunoreactivity (Figure 2, D and E, and Supplemental Table S2). Interestingly, this represents $84 \%$ of all p53negative cSCC tissue samples, indicating that accumulation of PRECSIT is associated with the absence of p53 expression in cSCC. A similar trend with PRECSIT accumulation and p53 immunoreactivity was also noted in $\mathrm{AK}$ and cSCCIS, in which PRECSIT accumulation was noted in $75 \%$ of all p53-negative lesions (Figure 2E and Supplemental Table S2). In addition, the portion of lesions with strong p53 staining intensity and PRECSIT accumulation was higher in cSCC tissues $(41 \%)$ when compared with AK and cSCCIS (10\%) (Figure 2E and Supplemental Table S2). In contrast, minority of the AK, cSCCIS (10\%) and cSCC tissue sections (10\%) detected with PRECSIT accumulation showed weak (+) p53 staining, as an indicative of a functional $\mathrm{p} 53$ in vivo (Figure 2E and Supplemental Table S2). 


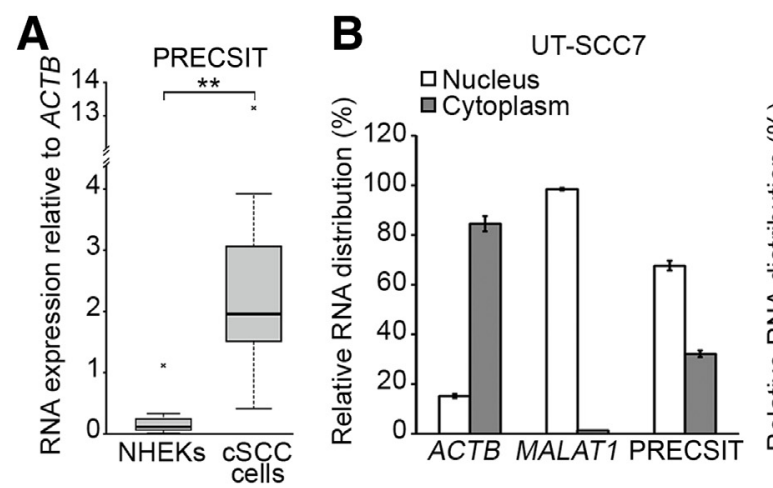

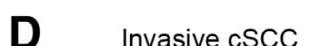

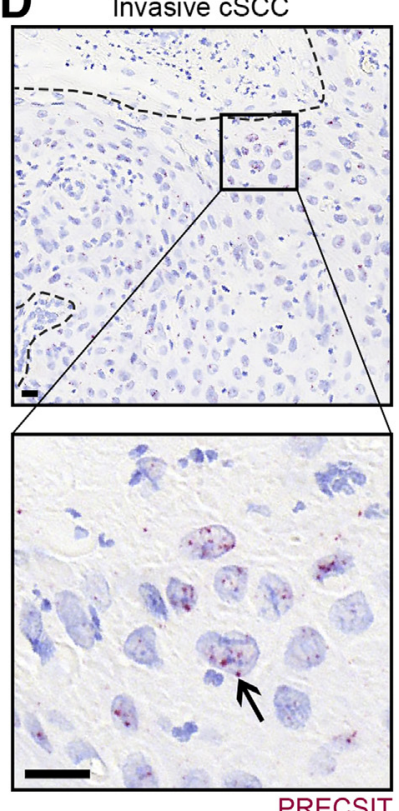

PRECSIT

H

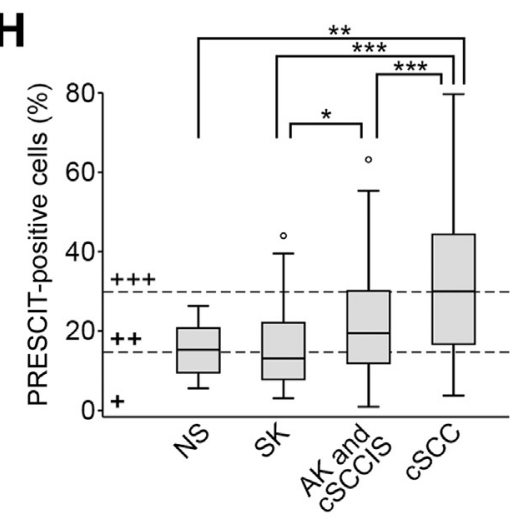

E $\quad \operatorname{cscc}$ in situ

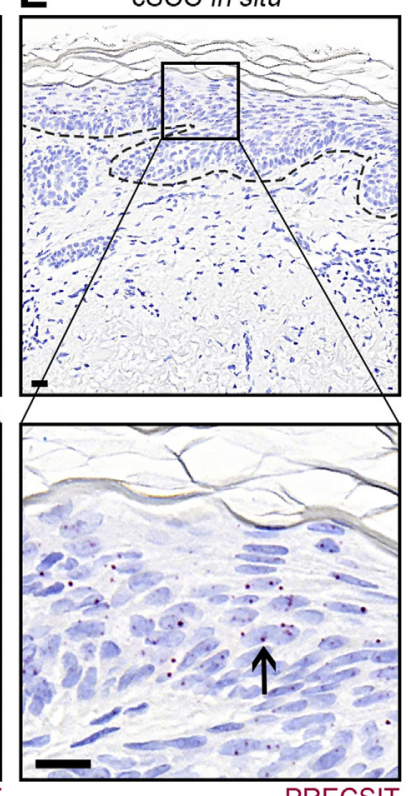

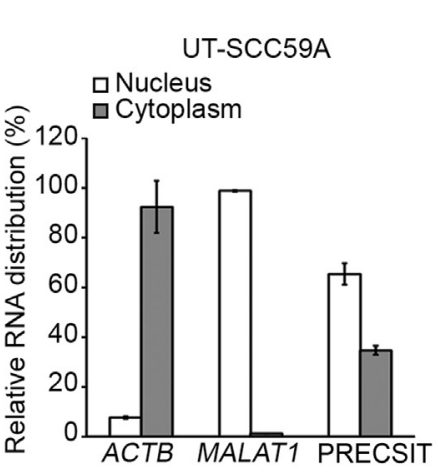

$\mathbf{F}$

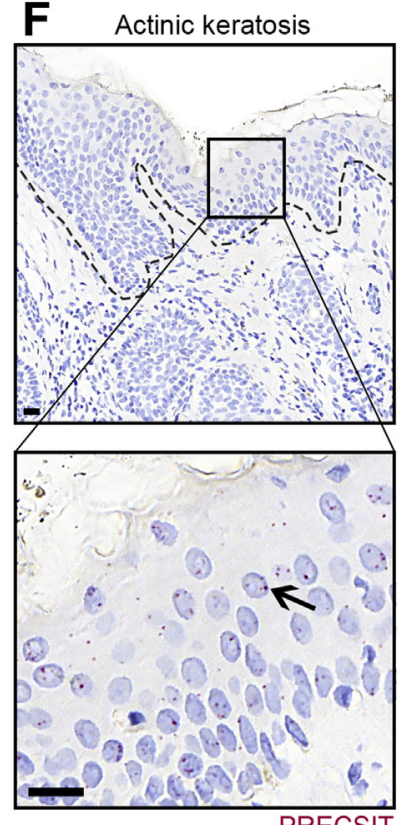

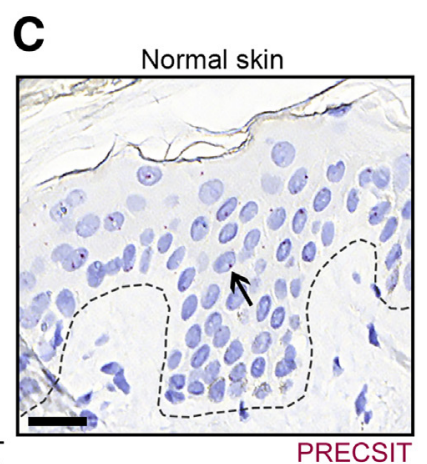

G Seborrheic keratosis

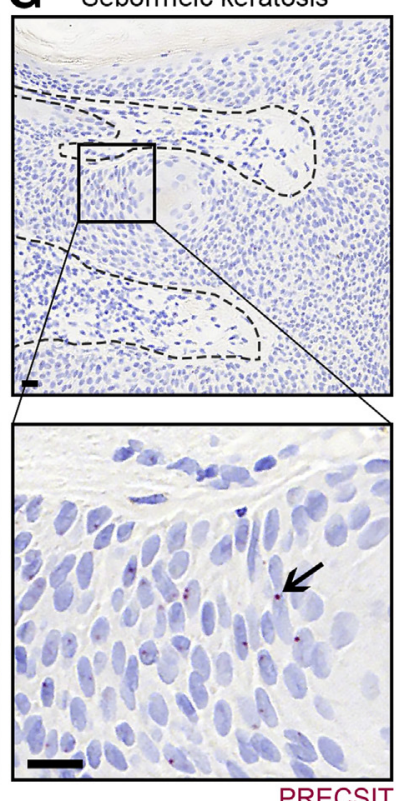

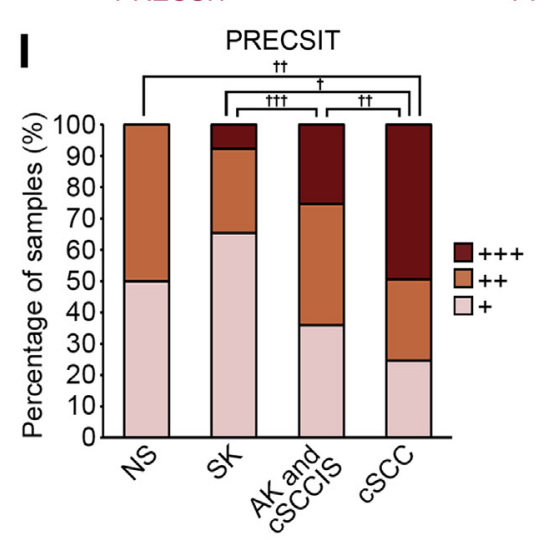

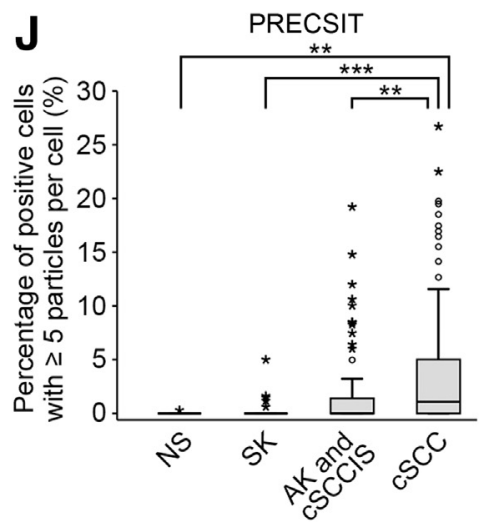

Figure 1 Expression of PRECSIT is specifically up-regulated in cutaneous squamous cell carcinoma (CSCC) cells in culture and in vivo. A: Expression of PRECSIT in normal human epidermal keratinocytes (NHEKs) and CSCC cell lines was measured using real-time quantitative PCR and corrected for the levels of $A C T B$ ( $\beta$-actin) mRNA. B: The subcellular localization of PRECSIT was determined by measuring its levels in the nuclear and cytoplasmic fractions of cSCC cells using real-time quantitative PCR. ACTB ( $\beta$-actin) mRNA and MALAT1 were used as controls for cytoplasmic and nuclear localization, respectively. C-G: Expression of PRECSIT was analyzed with RNA-ISH in paraffin-embedded tissue sections of normal skin (NS) (C), invasive CSCC (D), CSCC in situ (cSCCIS) (E), actinic keratosis (AK) (F), and seborrheic keratosis (SK) (G). Arrows indicate PRECSIT-positive cells; dashed lines, the boundary between the epidermal and dermal layers. Boxed areas are shown at higher magnification below. H: The number of PRECSIT-positive cells was compared with the total cell number in a section using QuPath bioimage analysis software version v0.1.2. Dashed lines depict the distribution of weak $(+)(<15 \%$ PRECSIT-positive cells), moderate $(++)(15 \%$ to $30 \%$ PRECSIT-positive cells), and strong $(+++)(>30 \%$ PRECSIT-positive cells) PRECSIT expression in distinct sample groups. I: Distribution of weak $(+)$, moderate $(++)$, and strong $(+++)$ PRECSIT expression in all sample groups. J: Percentage of cells detected with five or more PRECSIT particles compared with the total number of cells in a section in all groups. Data are expressed as medians \pm SD (A, H, and $\mathbf{J})$ or means \pm SD (B). $n=6$ NHEKs $(\mathbf{A}) ; n=7 \mathrm{cSCC}(\mathbf{A}) ; n=10$ NS (C); $n=81$ invasive $\operatorname{cSCC}(\mathbf{D}) ; n=25 \operatorname{cSCCIS}(\mathbf{E}) ; n=50 \mathrm{AK}(\mathbf{F}) ; n=26 \mathrm{SK}(\mathbf{G}) ; n=1 \mathrm{NS}(\mathbf{J}) ; n=5 \mathrm{SK}(\mathbf{J}) ; n=28 \mathrm{AK}$ and $\operatorname{cSCCIS}(\mathbf{J}) ; n=46 \operatorname{cSCC}(\mathbf{J}) .{ }^{*} P<0.05,{ }^{*} P<0.01$, and ${ }^{* * *} P<0.001$ (U-test); ${ }^{\dagger} P<0.05,{ }^{\dagger \dagger} P<0.01$, and ${ }^{\dagger \dagger \dagger} P<0.001$ (Fisher exact test). Scale bars $=20 \mu \mathrm{m}$. 


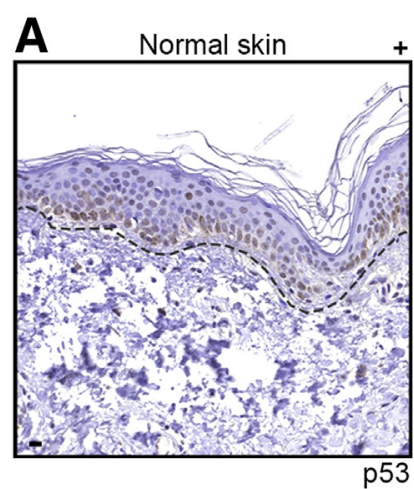

B
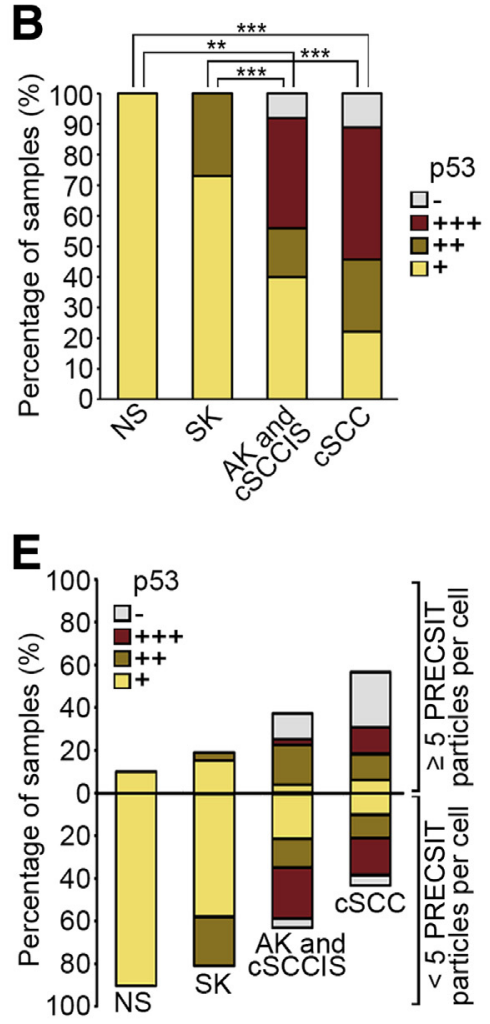
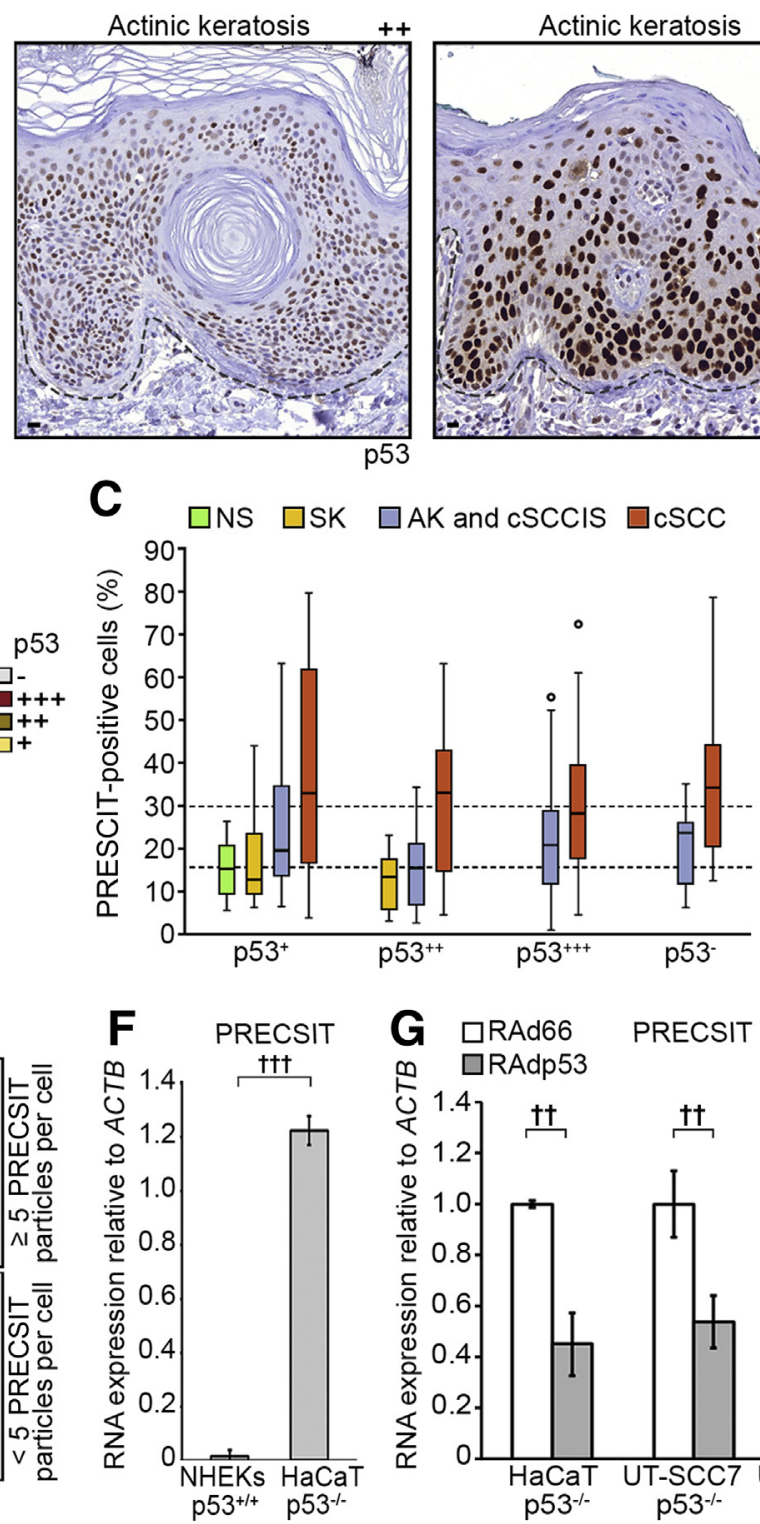
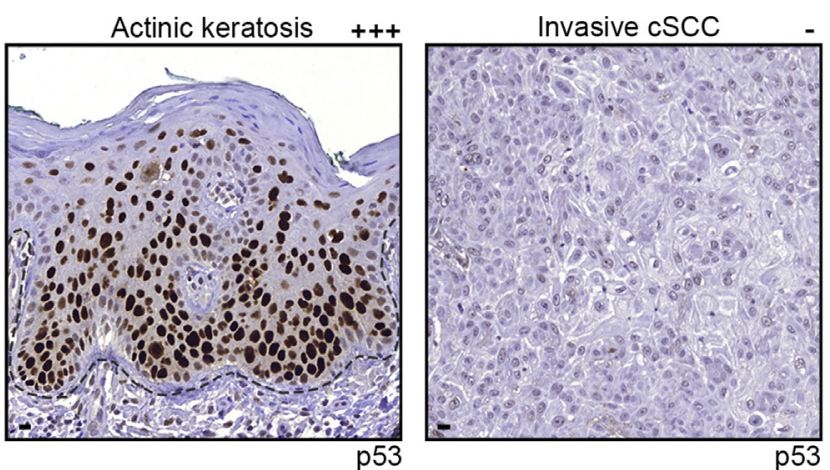

D
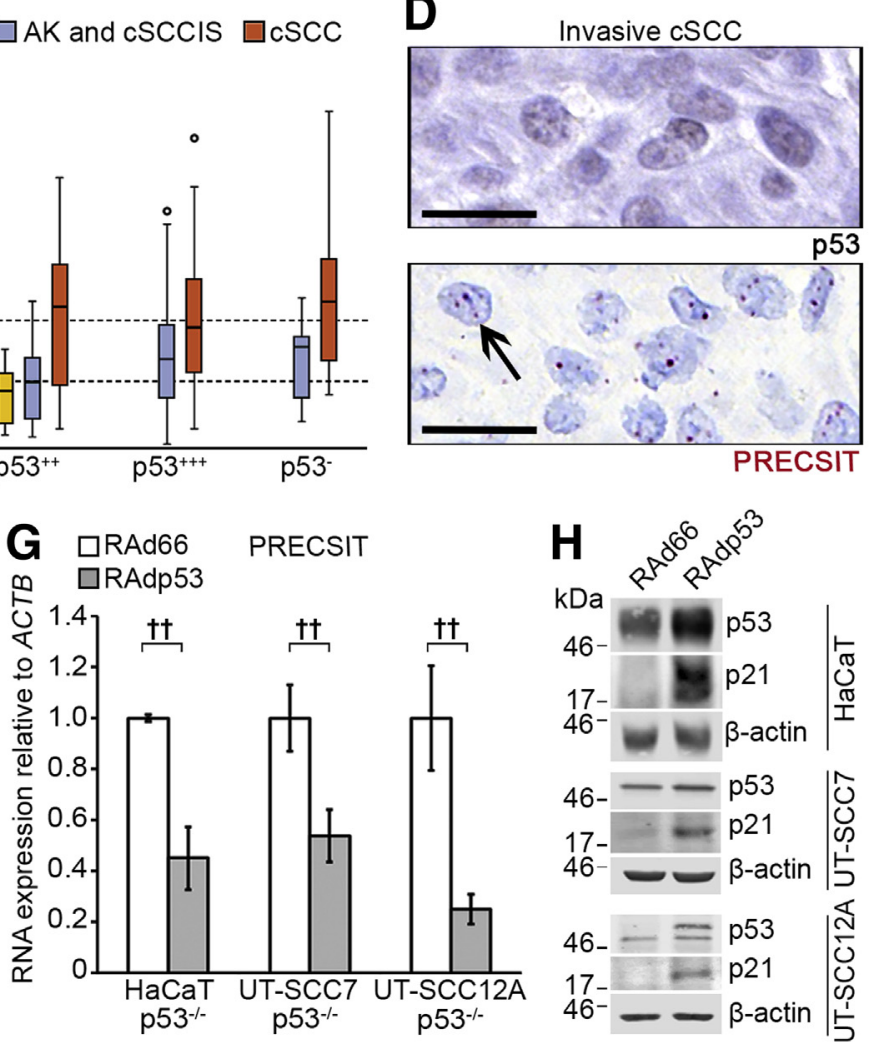

. 
Moreover, adenoviral delivery of the wild-type p53 into $\mathrm{HaCaT}$ or cSCC cells resulted in down-regulation of PRECSIT expression, showing that the expression of PRECSIT is regulated by p53 (Figure 2G). Adenoviral expression of p53 had no effect on cell viability (Supplemental Figure S4). A marked up-regulation of p21 expression, as a marker of p53 activity, ${ }^{38}$ was noted in cSCC cells after adenoviral delivery of the wild-type p53, as compared with control cells infected with empty vector (Figure $2 \mathrm{H}$ ).

\section{Knockdown of PRECSIT Down-Regulates Expression of STAT3 and MMP-1, MMP-3, MMP-10, and MMP-13 in cSCC Cells}

To identify molecular targets for PRECSIT, RNA-seq analysis was performed for three cSCC cell lines following knockdown of PRECSIT expression (Figure 3A). The most significant Gene Ontology terms associated with differentially expressed genes after PRECSIT knockdown included biological processes negative regulation of MAPK cascade $\left(P=8.2 \times 10^{-5}\right)$ and regulation of JAK-STAT cascade $\left(P=9.7 \times 10^{-4}\right)$ (Figure 3B). Differentially expressed genes after PRECSIT knockdown were also associated with Jak-STAT signaling $\left(P=1.1 \times 10^{-4}\right)$ by the Kyoto Encyclopedia of Genes and Genomes pathway analysis (Figure 3B). The Reactome pathway analysis revealed signaling by interleukins $\left(P=2.8 \times 10^{-5}\right)$ and cytokine signaling in immune system $\left(P=2.6 \times 10^{-3}\right)$ as the most significantly associated pathways with differentially expressed genes after PRECSIT knockdown (Figure 3B). One of the most frequent differentially expressed genes following PRECSIT knockdown was STAT3, which was among the top 40 most down-regulated genes (fold change $\log 2=-1.05$ ) (Figure $3 \mathrm{C}$ and Supplemental Table S4). In addition, genes for several MMPs, that is, $M M P 1, M M P 3, M M P 10$, and $M M P 13$ (fold change $\log 2=-1.07,-0.87,-2.16$, and -0.84 , respectively) were down-regulated after PRECSIT knockdown (Figure 3C and Supplemental Table S4). Decreased levels of activated and total STAT3 protein were noted by Western blot analysis of cSCC cells after PRECSIT knockdown (Figure 3D). Also, decreased mRNA (Figure 3E) and protein levels (Figure 3F) of MMP-1, MMP-3, MMP-10, and MMP-13 were noted in cSCC cells (UT-SCC7) after knockdown of PRECSIT.

\section{Knockdown of PRECSIT Inhibits Invasion of cSCC Cells}

To investigate PRECSIT function, cSCC cells in culture were transfected with two PRECSIT targeted siRNAs and negative control siRNA. Invasion of cSCC cells through three-dimensional collagen I matrix was significantly decreased after PRECSIT knockdown (Figure 4A). Knockdown of PRECSIT had no significant effect on proliferation of cSCC cells (Supplemental Figure S5). Inhibition of STAT3 activity by chemical inhibitor S31 in cSCC cells also resulted in a marked decrease in the production of MMP-1, MMP-3, MMP-10, and MMP-13 (Figure 4B). In addition, invasion of cSCC cells was also potently inhibited after STAT3 inhibition (Figure 4C). Together with the results of PRECSIT knockdown experiments, these observations provide evidence that PRECSIT promotes invasion of cSCC cells by up-regulating the expression of invasionassociated MMPs by regulating the levels of active STAT3.

\section{Knockdown of PRECSIT Suppresses Growth of cSCC Xenografts in Vivo}

The role of PRECSIT in invasion and growth of cSCC was further studied in vivo using xenograft model in SCID mice. cSCC cells were transfected with PRECSIT siRNA1 and control siRNA, incubated for 72 hours, and subsequently injected subcutaneously into the back of the SCID mice. Xenograft growth was measured twice a week, and tumors were harvested 16 days after implantation. PRECSIT knockdown resulted in significantly decreased xenograft tumor growth compared with control tumors (Figure 4D). No difference in the histology of xenografts was noted between the control and PRECSIT knockdown groups (Figure 4D). Interestingly, the highest PRECSIT expression was noted evenly localized at the invasive edge of the xenograft tumors, whereas the expression of PRECSIT in the inner tumor mass was low (Figure 4E). Localization of PRECSIT particles was noted in the cytoplasm and nucleus of the tumor cells, with prevalent appearance in the perinuclear region (Figure 4E). Furthermore, active STAT3 was detected in cSCC cells at the invasive edge of the xenograft tumor (Figure 4E).

\section{Discussion}

The role of lncRNAs in the cutaneous biology and pathogenesis of skin diseases is not well known. lncRNAs DANCR (differentiation antagonizing non-protein coding RNA) and TINCR (tissue differentiation-inducing nonprotein coding RNA) have been shown to regulate differentiation of epidermal keratinocytes, ${ }^{39,40}$ emphasizing the role of lncRNAs in maintenance of the normal structure and function of skin. Differential expression of lncRNAs has also been reported in psoriasis ${ }^{41}$ and in aberrant scarring. ${ }^{42}$ UV irradiation has been shown to affect the IncRNA expression profile in normal keratinocytes with a differential expression profile after exposure to UVA and UVB. ${ }^{43,44}$ Although several IncRNAs have been characterized in melanoma, ${ }^{45}$ the role of lncRNAs in keratinocyte cancers is poorly known. The function of lncRNA PICSAR in the progression of human $\mathrm{CSCC}$ has been previously identified and characterized. ${ }^{22,23}$ In addition, recent studies have implicated lncRNAs MALAT1, LINC00319, and SMRT-2 in $\mathrm{CSCC}^{46-48}$ 
A

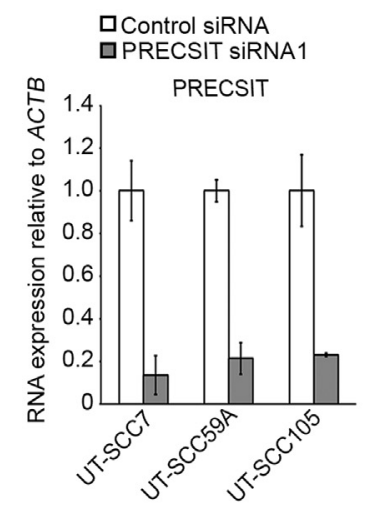

C

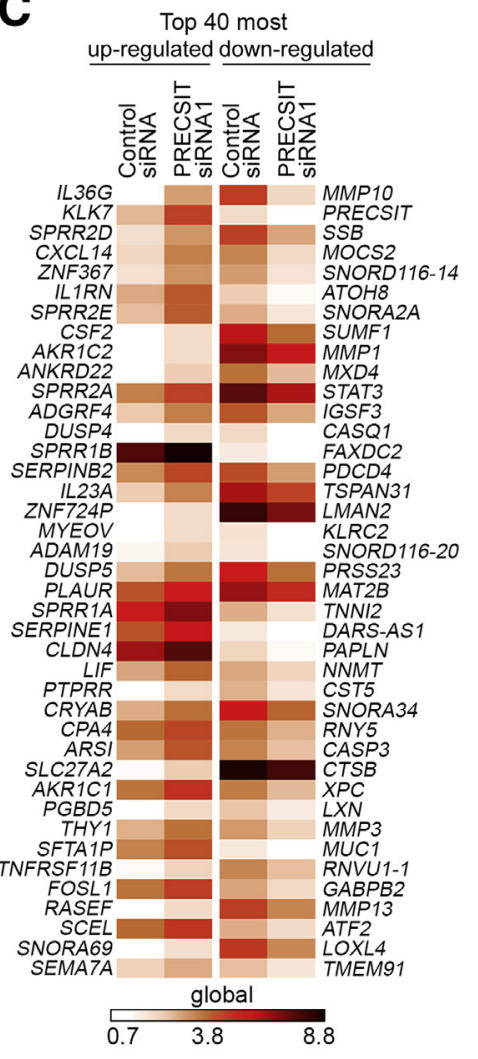

B

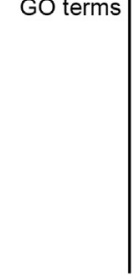

KEGG
pathways

Reactome pathways

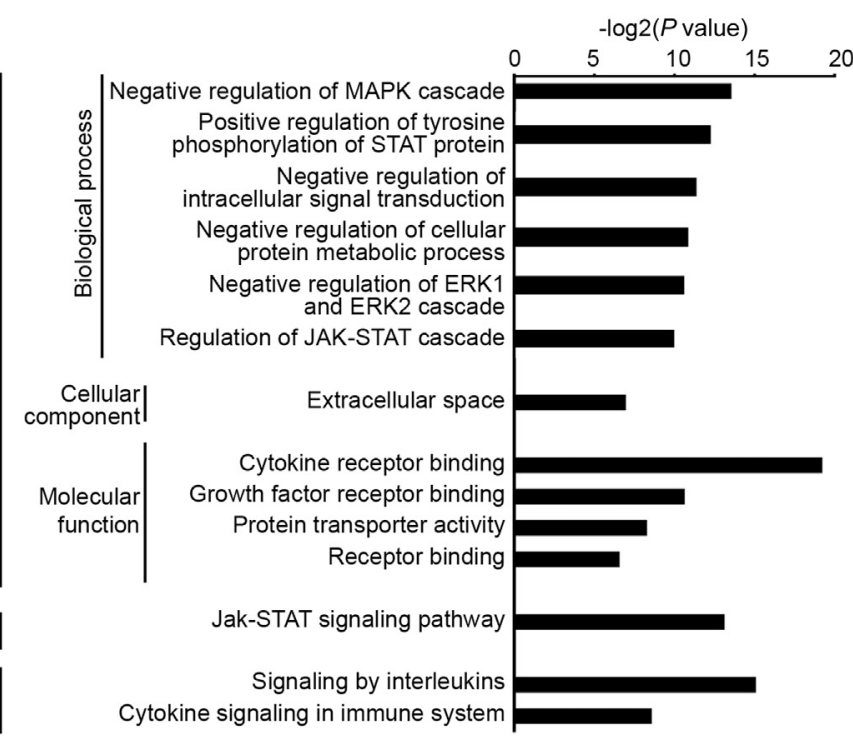

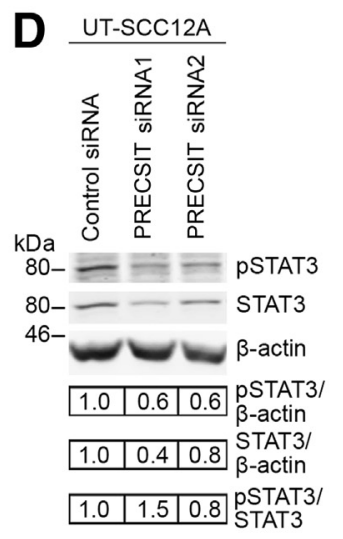

E

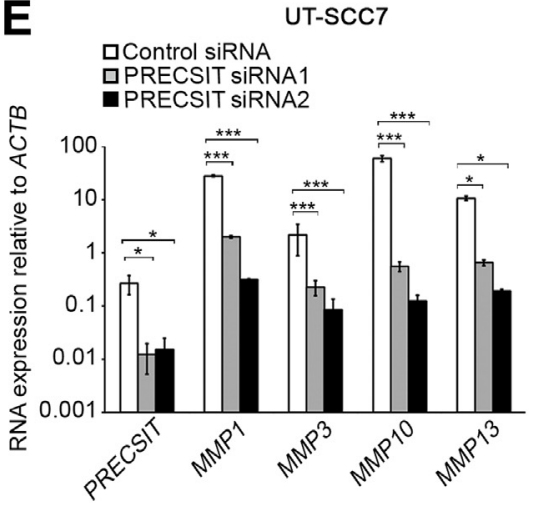

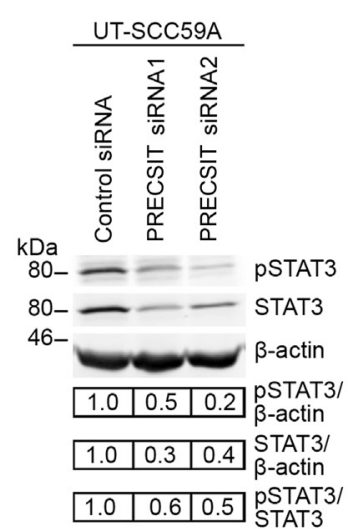

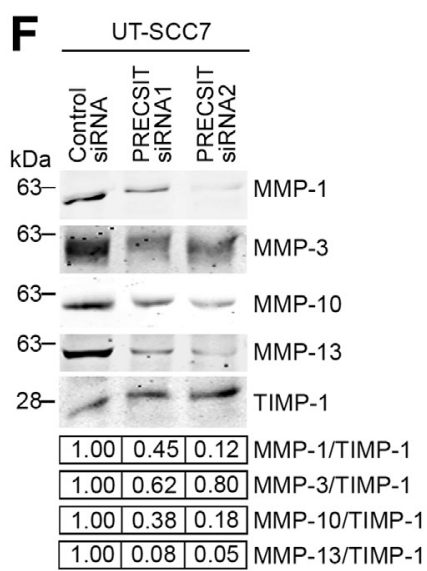

Figure 3 PRECSIT regulates expression of activated STAT3 and matrix metalloproteinases. A: PRECSIT expression was silenced in CSCC cells (UT-SCC7, UT-SCC59A, and UT-SCC105) by transfecting cells with PRECSIT siRNA1 or negative control siRNA. PRECSIT expression was determined 72 hours after transfection by real-time quantitative PCR and corrected for ACTB ( $\beta$-actin) mRNA levels in the same samples. B: Gene Ontology (G0), Kyoto Encyclopedia of Genes and Genomes (KEGG), and Reactome pathway enrichment analysis of differentially expressed genes $(P<0.01$, fold change log2 $>1$ between the control siRNA group and PRECSIT siRNA1 group) in the RNA-seq of PRECSIT knockdown CSCC cells. C: Heatmap showing the 40 most up- and down-regulated genes after PRECSIT knockdown (fold change log2 > 0.75). D: Expression of phosphorylated and total STAT3 in cSCC cells 72 hours after PRECSIT knockdown determined by Western blot analysis. $\beta$-Actin was used as a reference. E: Expression of MMP1, MMP3, MMP10, and MMP13 mRNA was determined from UT-SCC7 cell lysates 72 hours after PRECSIT knockdown and corrected for ACTB ( $\beta$-actin) mRNA levels in the same samples. F: Expression of MMP-1, MMP-3, MMP-10, and MMP-13 at protein level was determined by Western blotting analysis from conditioned media of UT-SCC7 cells 72 hours after PRECSIT knockdown. The level of tissue inhibitor of matrix metalloproteinases 1 (TIMP-1) expression was used as a loading control reference. Data are expressed as means \pm SD. $n=3$ samples (A and $\mathbf{E}$ ). ${ }^{*} P<0.05,{ }^{* *} P<0.001$ ( $t$-test). 
A

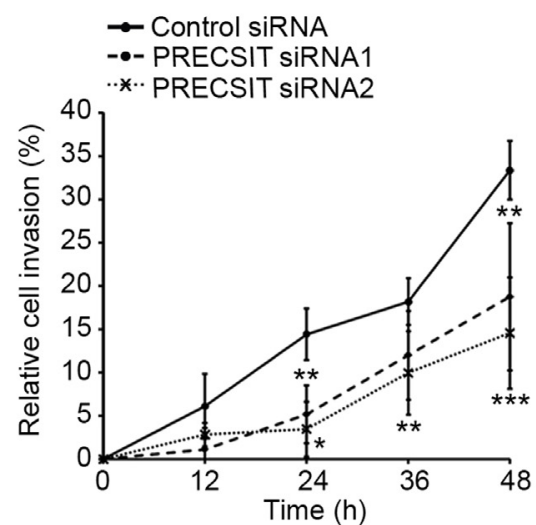

B

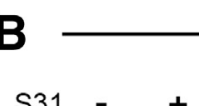

S31
kDa
$80-$

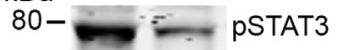

$80-\longrightarrow$ STAT3

$48-$

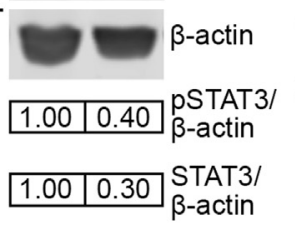

UT-SCC7

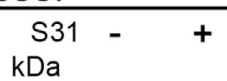

$\mathrm{kDa}$

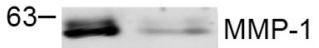

63-

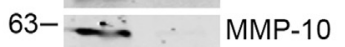

$63-\ldots M M P-13$

$28-$

\section{\begin{tabular}{|l|l|}
\hline 1.00 & 0.20 \\
\hline 1.00 & 0.04 \\
\hline
\end{tabular}} \begin{tabular}{|l|l|l|}
\hline 1.00 & 0.04 & MMP-3/TIMP-1 \\
\hline \hline 1.00 & 0.03 \\
\hline
\end{tabular} \begin{tabular}{|l|l|l|}
\hline 1.00 & 0.03 & MMP-10/TIMP-1 \\
\hline 1.00 & 0.40 \\
\hline
\end{tabular} \begin{tabular}{|l|l|}
\hline 1.00 & 0.40 \\
\hline
\end{tabular}

\section{UT-SCC59A}

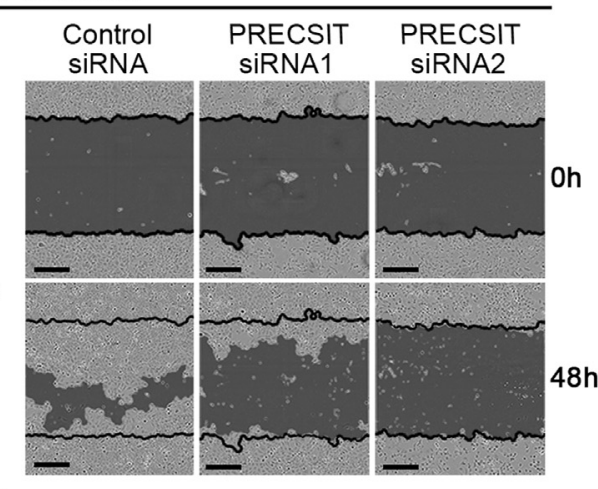

UT-SCC7

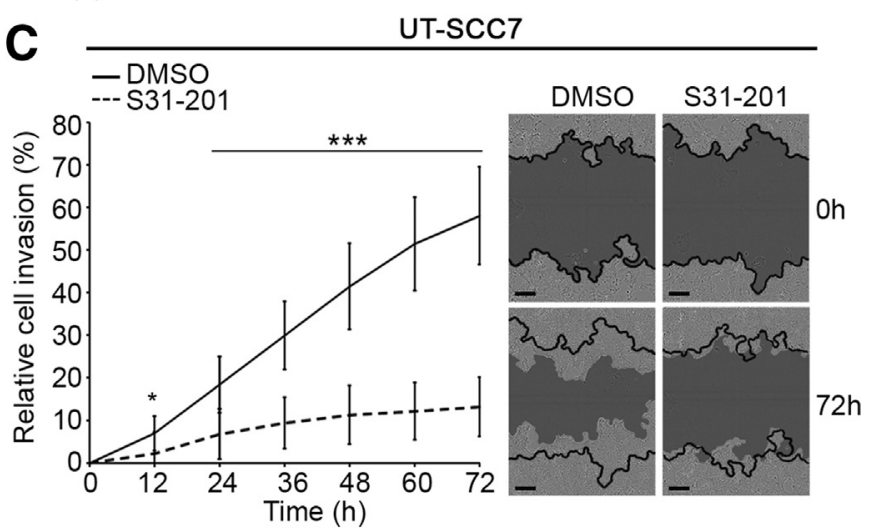

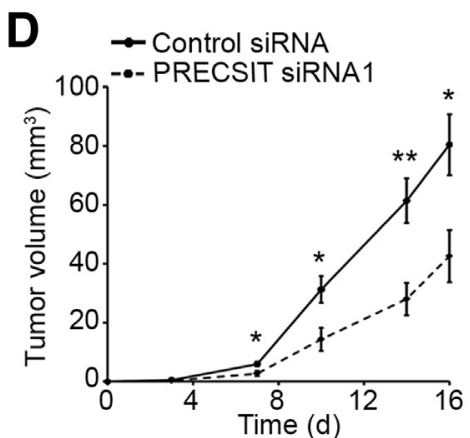

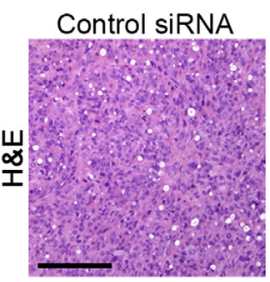

E

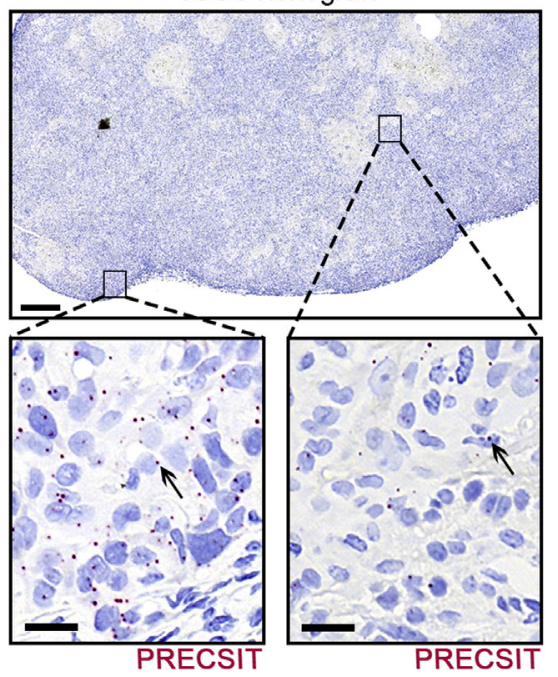

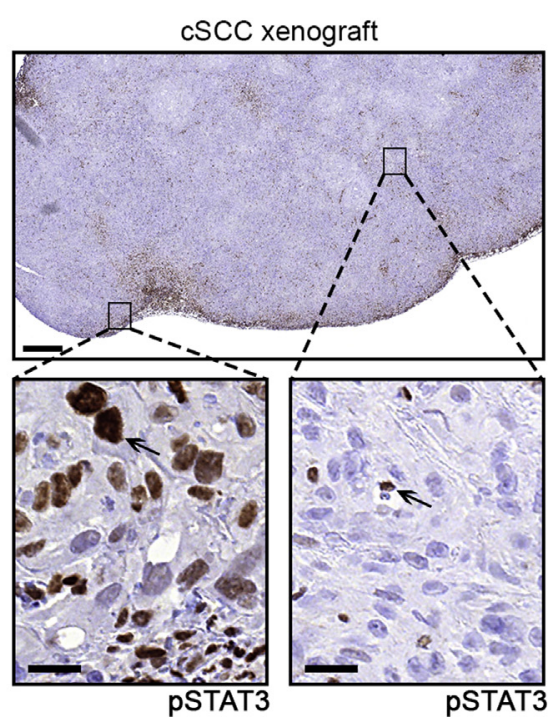

Figure 4 PRECSIT knockdown inhibits CSCC cell invasion and growth of CSCC xenografts in vivo. A: CSCC cells were transfected with negative control siRNA or two different PRECSIT siRNAs and plated on collagen I 24 hours after transfection. Cell monolayer was scratched and collagen I solution was added in wells and let to polymerize. Cell culture medium with $0.5 \%$ fetal calf serum was added and cell invasion was imaged using the IncuCyte Z00M real-time cell imaging system. Representative images of the cell invasion assay are shown. B: CSCC cells (UT-SCC7) were treated with STAT3 inhibitor S31-201 (100 $\mu \mathrm{mol} / \mathrm{L}$ ) for 48 hours, and expression of phosphorylated and total STAT3 was determined from cell lysates by Western blot analysis. $\beta$-Actin was used as a reference. Expression of MMP-1, MMP-3, MMP-10, and MMP-13 was determined from conditioned media and the level of tissue inhibitor of matrix metalloproteinases 1 (TIMP-1) expression was used as a reference. C: cSCC cells (UT-SCC7) were plated on collagen I and treated with STAT3 inhibitor S31-201 (100 $\mu \mathrm{mol} / \mathrm{L})$ overnight. Cell invasion through three-dimensional collagen I was imaged using IncuCyte Z00M real-time cell imaging system. Representative images of the assay are shown. D: cSCC cells (UT-SCC7) were transfected with PRECSIT targeted siRNA1 or negative control siRNA and injected subcutaneously into the back of severe combined immunodeficient mice. Tumor growth was measured twice a week. Histology of the tumors was analyzed in hematoxylin and eosin (H\&E) stained tumor sections. E: Expression of PRECSIT and active STAT3 (pSTAT3) was determined in CSCC xenograft tumors with RNA-ISH and immunohistochemistry. Arrows indicate PRECSIT-positive cells. Boxed areas are shown at higher magnification below. Data are expressed as means \pm SD (A and C) or means \pm SEM (D). $n=5$ control siRNA, PRECSIT SIRNA1, and PRECSIT siRNA2 (A); $n=10$ DMSO and S31201 (C); $n=6$ control siRNA (D); $n=8$ PRECSIT siRNA1 (D). ${ }^{*} P<0.05,{ }^{*} P<0.01$, and ${ }^{* * *} P<0.001$ (t-test). Scale bars: $300 \mu \mathrm{m}$ (A and C); $100 \mu \mathrm{m}$ (D); $500 \mu \mathrm{m}$ (E, top row); $20 \mu \mathrm{m}$ (E, bottom row). 
Here, the authors have characterized the role of lncRNA PRECSIT (LINCO0346) in the progression of cSCC. Based on the whole-transcriptome analysis in the authors' previous work, PRECSIT was identified among the most significantly up-regulated lncRNAs in cSCC cells with very low expression in NHEKs. ${ }^{22}$ Recently, up-regulation of PRECSIT has been reported in breast, bladder, pancreatic, non-small-cell lung, and hepatocellular cancers, ${ }^{49-53}$ but its subcellular localization, expression in situ, or the functional role in these cancers have not been investigated. In this study, marked upregulation of PRECSIT expression was noted in cSCC cells, and primarily nuclear localization was detected in cSCC cells by analyzing the subcellular RNA fractions. Marked expression of PRECSIT was detected in tumor cells in cSCC in vivo, whereas the expression was very low in NS. PRECSIT expression was also higher in AK lesions and cSCC in situ when compared with NS or benign epidermal papillomas, SK, suggesting a specific role for PRECSIT at the early stage of cSCC development.

The mutation frequency of cSCC is higher than in melanoma or in other squamous cell carcinomas. ${ }^{10,12,13}$ Mutational inactivation of the tumor suppressor TP53 gene is an early event in epidermal carcinogenesis, leading to genomic instability in keratinocytes and further malignant transformation. Interestingly, TP53 mutations are not detected in SK, benign skin tumors with a clear UV mutation signature. ${ }^{54}$ The mutational status of the p53 protein is routinely assessed by visualizing the nuclear accumulation of the mutant p53 by immunohistochemical analysis. ${ }^{55}$ Total absence of the immunoreactive p53 also implies nonsense mutation in TP53 resulting in lack of functional p53. ${ }^{56}$ Accordingly, strong p53 staining or absence of p53 was detected only in malignant tissues, cSCC, cSCCIS, and AK. The p53 staining intensities in our panel of tissue sections of NS, SK, AK, cSCC in situ, and invasive cSCC are also in accordance with the previous reports, where strong or moderate nuclear accumulation of p53 has been noted early in cSCC carcinogenesis. ${ }^{57-59}$

PRECSIT expression was examined together with the p53 expression levels in vivo in parallel tissue sections. Low or moderate PRECSIT expression was noted in the majority of the NS and SK tissues with low p53 staining intensity, suggesting that the expression of PRECSIT is suppressed by functional p53 in vivo in these lesions. A high level of variation in PRECSIT expression level and p53 staining intensities was noted in AK, cSCCIS, and invasive cSCC tissues, but the percentage of PRECSIT-positive cells did not correlate with p53 mutational status. However, in the majority of cSCC tissue sections, high PRECSIT expression (five or more PRECSIT particles per cell) was associated with negative $\mathrm{p} 53$ staining, suggesting that a high PRECSIT copy number per cell in cSCC cells in vivo is due to the absence of p53. Negative p53 immunoreactivity is presumably a result of a nonsense mutation in TP53, which results in production of truncated and nonfunctional p53. ${ }^{55,56}$
These results suggest that very low basal level of PRECSIT is important for normal growth and differentiation of epidermal keratinocytes, whereas overexpression of PRECSIT due to mutationally inactivated p53 is associated with development and progression of cSCC. Significantly higher expression of PRECSIT was also noted in nontumorigenic $\mathrm{HaCaT}$ cells, which harbor homozygously mutated p53, as compared with NHEKs with functional p53. Moreover, adenoviral delivery of wild-type p53 into cSCC cells harboring mutated p53 resulted in potent down-regulation of PRECSIT expression. Several p53-regulated lncRNAs have been identified so far, ${ }^{60}$ and certain lncRNAs including MALAT1, RoR, and MEG3 have in turn been shown to regulate p53. ${ }^{61-63}$ No p53 binding site was found within the PRECSIT gene promoter region (GeneHancer identifier GH13J110868), suggesting that the expression of PRECSIT is not directly regulated by p53. This is in accordance with previous observations that $\mathrm{p} 53$ is a transcriptional activator and that transcriptional repression by $\mathrm{p} 53$ is indirect. ${ }^{64}$ Nevertheless, these results identify PRECSIT as a lncRNA specifically overexpressed in cSCC and regulated by p53 signaling.

RNA-seq and bioinformatic analysis of cSCC cells after PRECSIT knockdown revealed Jak-STAT signaling as one of the most potential targets for PRECSIT. In addition, significant down-regulation of STAT3 mRNA and protein levels after PRECSIT knockdown was detected resulting in potent reduction in the levels of activated STAT3, indicating that the effect of PRECSIT is mediated via STAT3 signaling in cSCC cells. Previously, STAT3 has been shown to play an important role in cutaneous wound healing by promoting keratinocyte migration. ${ }^{63}$ In addition, aberrant STAT3 activity has been shown to contribute to cutaneous carcinogenesis and cancer progression by regulating immune suppression. ${ }^{65}$

STAT3 functions as a transcriptional activator of several MMP genes, including $M M P I^{66}$ and $M M P 3,{ }^{67}$ and it can in this way promote cell invasion. Accordingly, knockdown of PRECSIT resulted in down-regulation in the expression of collagenase-1 (MMP-1), collagenase-3 (MMP-13), stromelysin-1 (MMP-3), and stromelysin-2 (MMP-10). Knockdown of PRECSIT inhibited cSCC cell invasion through collagen type I matrix, and inhibition of STAT3 resulted in decreased cSCC cell invasion and in downregulation of the expression of MMP-1, MMP-3, MMP10 , and MMP-13. It has been previously shown that MMP-13 is specifically expressed by tumor cells in cSCCs and head and neck squamous cell carcinomas. ${ }^{68,69}$ The expression of MMP-13 in head and neck squamous cell carcinoma correlates with the local invasion in head and neck squamous cell carcinoma, and its expression in head and neck squamous cell carcinoma cells is potently inhibited by $553 .^{26,70}$ Elevated expression of MMP-3 and MMP-10 has also been reported in $\mathrm{cSCC} .^{71}$ It is conceivable that MMP-3 and MMP-10 can also promote cSCC progression by activating latent MMPs, including MMP-1 and 
MMP-13. ${ }^{72}$ Together these results identify a novel mechanism how p53 signaling inhibits invasion of cSCC cells by suppressing the expression of PRECSIT. These results also provide mechanistic evidence for the role of STAT3 in mediating the effect of PRECSIT on invasion of cSCC cells by generating a network of potent invasion proteinases in the tumor microenvironment of cSCCs (Figure 5).

Mutant p53 may also aid in the modification of the tumor microenvironment by modulating extracellular matrix remodeling, by stimulating secretion of inflammatory cytokines, and regulating crosstalk between tumor and stromal cells. ${ }^{73}$ Moreover, mutant p53 has been shown to bind and constitutively activate STAT3, and hence aid in the progression of colorectal cancer. ${ }^{74}$ Here, the authors show that PRECSIT accumulation in cSCC tumor cells is associated with the absence of $\mathrm{p} 53$, but these results suggest that the expression of PRECSIT is indirectly regulated by p53. As the accumulation of PRECSIT is noted mainly in the cSCC tumor cells lacking the wild-type or mutant p53 expression, it can be suggested that mutant p53 retains some of the suppressive effect of wild-type p53 on PRECSIT expression.

Knockdown of PRECSIT results in significant inhibition of cSCC xenograft growth in vivo. The highest level of PRECSIT expression in the control xenografts was detected at the edge of tumors, analogous to localization of active STAT3, indicating that PRECSIT is associated with tumor invasion and proteolytic activity of MMPs at the invasive edge of tumors. ${ }^{75}$ It is likely that the inhibition of tumor growth after PRECSIT knockdown is a result of impaired cSCC tumor cell implantation and organization of the extracellular matrix at the early stage of tumor formation due to decreased proteolytic activity. In this respect, it is important to note, that the structure of basement membrane is altered in $\mathrm{AK}$ and cSCCIS, indicating that alterations in the microenvironment of the premalignant and noninvasive lesions is important in their progression to invasive $\mathrm{cSCC} .{ }^{76}$

In conclusion, the authors have identified a lncRNA, PRECSIT, that is specifically expressed by cSCC cells in culture and in vivo, and show that it is regulated by $\mathrm{p} 53$ (Figure 5). The levels of activated transcription factor STAT3 are up-regulated by PRECSIT, and this in turn upregulates the expression of several invasion-associated MMPs, that is, MMP-1 and MMP-13, which cleave fibrillar collagens, and MMP-3 and MMP-10, which can cleave a multitude of other extracellular matrix and basement membrane components, including type IV collagen, fibronectin, and laminin, and can activate latent MMP-1 and MMP-13. ${ }^{68}$ In this way, simultaneous up-regulation of these MMPs generates a potent proteolytic network capable of cleaving the extracellular matrix in the tumor microenvironment of cSCC. On the basis of these findings, the authors propose that PRECSIT promotes progression of cSCC by specifically regulating invasion of cSCC cells via STAT3 signaling. Accordingly, PRECSIT may serve as a novel potential biomarker and therapeutic target in $\mathrm{cSCC}$.
Normal skin

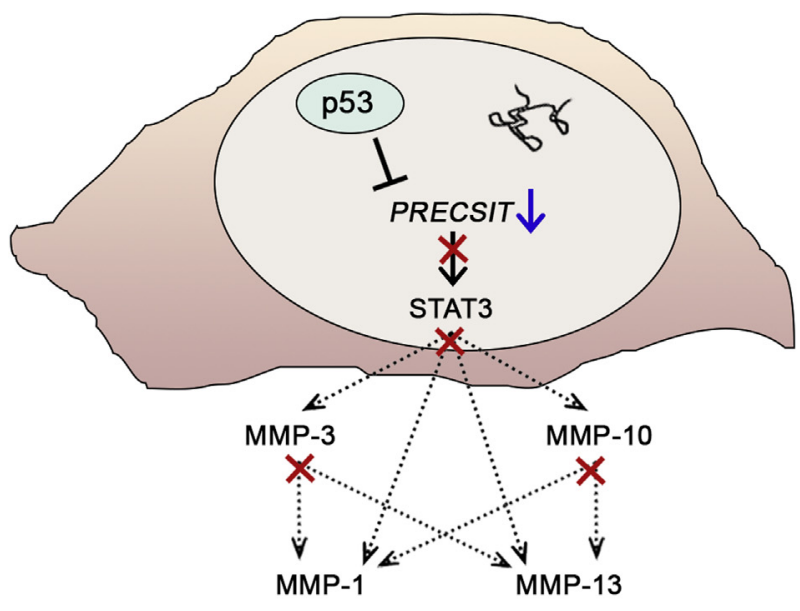

$\operatorname{cscc}$

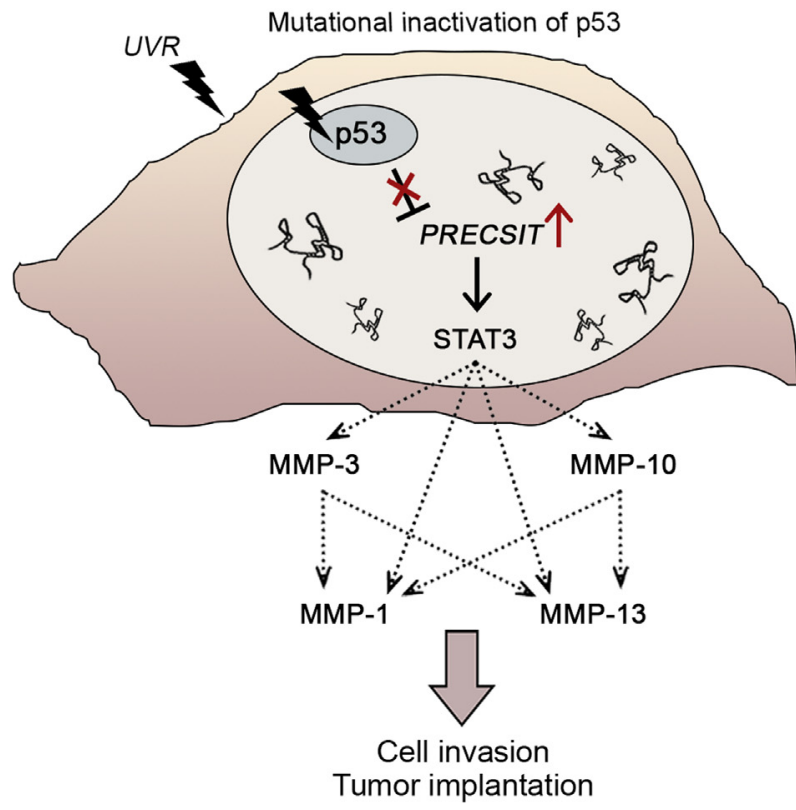

Figure 5 Proposed molecular model for the mechanistic role of PRECSIT in cutaneous squamous cell carcinoma (CSCC). Low level of PRECSIT expression is maintained in normal epidermal keratinocytes by functional $p 53$. The blue arrow indicates down-regulation of PRECSIT expression; red crosses, blockage of the downstream signaling. In CSCC cells, mutational inactivation of p53, particularly nonsense mutations leading to premature translation termination and lack of functional p53 protein, results in up-regulation and accumulation of PRECSIT in the nucleus. The red arrow indicates up-regulation of PRECSIT expression. Elevated PRECSIT expression contributes to STAT3 activation and up-regulation of the matrix metalloproteinases collagenase-1 (MMP-1), collagenase-3 (MMP-13), stromelysin-1 (MMP-3), and stromelysin-2 (MMP10). MMP-3 and MMP-10 are capable of degrading several extracellular matrix (ECM) components, including basement membrane type IV collagen, fibronectin, and laminin. They also activate latent collagenases MMP-1 and MMP-13, capable of cleaving fibrillar collagens type I and III in the dermal ECM. The proteolytic remodeling of ECM and basement membrane by MMPs is essential for CSCC cell invasion and tumor cell implantation, and it may also promote progression of premalignant and noninvasive malignant lesions AK and CSCCIS to fully invasive and metastatic CSCC. 


\section{Acknowledgments}

We thank Johanna Markola and Sinikka Collanus for their expert technical assistance; Dr. Reidar Grénman for cSCC cell lines and tumor samples; Dr. Tero Vahlberg for assistance with statistical analysis; Dr. Norbert E. Fusenig (The German Cancer Research Center, Heidelberg, Germany) for HaCaT cells; Dr. Prem Seth (Des Moines University, Des Moines, IA) for recombinant adenovirus RAdp53 containing the gene for human wild-type p53; Dr. Gavin W.J. Wilkinson (University of Cardiff, Wales, UK) for human wild-type p53; the staff at the Histology Core of the Institute of Biomedicine at the University of Turku; and the staff at the Bioinformatics Unit and the Cell Imaging Core of the Turku Bioscience Centre for their help and expertise.

\section{Author Contributions}

M.P., L.N., and V.-M.K. designed the research; V.-M.K. directed the study; P.R. and M.F. provided the patient samples; J.P. and S.P. provided the normal skin samples and NHEKs; M.P. performed the experiments and analyzed the data; P.R. and M.K. analyzed the histology of the tissue samples; M.P., L.N., and V.-M.K. wrote the manuscript; L.N. and V.-M.K. acquired the research funding.

\section{Supplemental Data}

Supplemental material for this article can be found at https://doi.org/10.1016/j.ajpath.2019.10.019.

\section{References}

1. Morris KV, Mattick JS: The rise of regulatory RNA. Nat Rev Genet 2014, 15:423-437

2. Marchese FP, Raimondi I, Huarte M: The multidimensional mechanisms of long noncoding RNA function. Genome Biol 2017, 18:206

3. Gloss BS, Dinger ME: The specificity of long noncoding RNA expression. Biochim Biophys Acta 2016, 1859:16-22

4. Bhan A, Soleimani M, Mandal SS: Long noncoding RNA and cancer: a new paradigm. Cancer Res 2017, 77:3965-3981

5. Qi P, Zhou XY, Du X: Circulating long non-coding RNAs in cancer: current status and future perspectives. Mol Cancer 2016, 15:39

6. Green AC, Olsen CM: Cutaneous squamous cell carcinoma: an epidemiological review. Br J Dermatol 2017, 177:373-381

7. Nehal KS, Bichakjian CK: Update on keratinocyte carcinomas. N Engl J Med 2018, 379:363-374

8. Que SKT, Zwald FO, Schmults CD: Cutaneous squamous cell carcinoma: incidence, risk factors, diagnosis, and staging. J Am Acad Dermatol 2018, 78:237-247

9. Ratushny V, Gober MD, Hick R, Ridky TW, Seykora JT: From keratinocyte to cancer: the pathogenesis and modeling of cutaneous squamous cell carcinoma. J Clin Invest 2012, 122:464E72

10. Pickering CR, Zhou JH, Lee JJ, Drummond JA, Peng SA, Saade RE, Tsai KY, Curry JL, Tetzlaff MT, Lai SY, Yu J, Muzny DM, Doddapaneni H, Shinbrot E, Covington KR, Zhang J, Seth S, Caulin C, Clayman GL, El-Naggar AK, Gibbs RA, Weber RS, Myers JN, Wheeler DA, Frederick MJ: Mutational landscape of aggressive cutaneous squamous cell carcinoma. Clin Cancer Res 2014, 20:658-692

11. Durinck S, Ho C, Wang NJ, Liao W, Jakkula LR, Collisson EA, Pons J, Chan SW, Lam ET, Chu C, Park K, Hong SW, Hur JS, Huh N, Neuhaus IM, Yu SS, Grekin RC, Mauro TM, Cleaver JE, Kwok PY, LeBoit PE, Getz G, Cibulskis K, Aster JC, Huang H, Purdom E, Li J, Bolund L, Arron ST, Gray JW, Spellman PT, Cho RJ: Temporal dissection of tumorigenesis in primary cancers. Cancer Discov 2011, 1:137-143

12. Cho RJ, Alexandrov LB, den Breems NY, Atanasova VS, Farshchian M, Purdom E, et al: APOBEC mutation drives early-onset squamous cell carcinomas in recessive dystrophic epidermolysis bullosa. Sci Transl Med 2018, 10:eaas9668

13. South AP, Purdie KJ, Watt SA, Haldenby S, den Breems N, Dimon M, Arron ST, Kluk MJ, Aster JC, McHugh A, Xue DJ, Dayal JH, Robinson KS, Rizvi SH, Proby CM, Harwood CA, Leigh IM: NOTCH1 mutations occur early during cutaneous squamous cell carcinogenesis. J Invest Dermatol 2014, 134: $2630-2638$

14. Riihilä PM, Nissinen LM, Ala-Aho R, Kallajoki M, Grénman R, Meri S, Peltonen S, Peltonen J, Kähäri VM: Complement factor H: a biomarker for progression of cutaneous squamous cell carcinoma. J Invest Dermatol 2014, 134:498-506

15. Riihilä $\mathrm{P}$, Nissinen L, Farshchian M, Kivisaari A, Ala-Aho R, Kallajoki M, Grénman R, Meri S, Peltonen S, Peltonen J, Kähäri VM: Complement factor I promotes progression of cutaneous squamous cell carcinoma. J Invest Dermatol 2015, 135:579-588

16. Riihilä P, Nissinen L, Farshchian M, Kallajoki M, Kivisaari A, Meri S, Grénman R, Peltonen S, Peltonen J, Pihlajaniemi T, Heljasvaara R, Kähäri VM: Complement component C3 and complement factor B promote growth of cutaneous squamous cell carcinoma. Am J Pathol 2017, 187:1186-1197

17. Gambichler T, Gnielka M, Rüddel I, Stockfleth E, Stücker M, Schmitz L: Expression of PD-L1 in keratoacanthoma and different stages of progression in cutaneous squamous cell carcinoma. Cancer Immunol Immunother 2017, 66:1199-1204

18. Farshchian M, Kivisaari A, Ala-Aho R, Riihilä P, Kallajoki M, Grénman R, Peltonen J, Pihlajaniemi T, Heljasvaara R, Kähäri VM: Serpin peptidase inhibitor clade A member 1 (SerpinA1) is a novel biomarker for progression of cutaneous squamous cell carcinoma. Am J Pathol 2011, 179:1110-1119

19. Farshchian $M$, Nissinen L, Siljamäki E, Riihilä $P$, Toriseva $M$, Kivisaari A, Ala-Aho R, Kallajoki M, Veräjänkorva E, Honkanen HK, Heljasvaara R, Pihlajaniemi T, Grénman R, Peltonen J, Peltonen S, Kähäri VM: EphB2 promotes progression of cutaneous squamous cell carcinoma. J Invest Dermatol 2015, 135:1882-1892

20. Farshchian M, Nissinen L, Siljamäki E, Riihilä P, Piipponen M, Kivisaari A, Kallajoki M, Grénman R, Peltonen J, Peltonen S, Quint KD, Bavinck JNB, Kähäri VM: Tumor cell-specific AIM2 regulates growth and invasion of cutaneous squamous cell carcinoma. Oncotarget 2017, 8:45825-45836

21. Bosic MM, Brasanac DC, Stojkovic-Filipovic JM, Zaletel IV, Gardner JM, Cirovic SL: Expression of p300 and p300/CBP associated factor (PCAF) in actinic keratosis and squamous cell carcinoma of the skin. Exp Mol Pathol 2016, 100:378-385

22. Piipponen M, Nissinen L, Farshchian M, Riihilä P, Kivisaari A, Kallajoki M, Peltonen J, Peltonen S, Kähäri VM: Long noncoding RNA PICSAR promotes growth of cutaneous squamous cell carcinoma by regulating ERK1/2 activity. J Invest Dermatol 2016, 136: $1701-1710$

23. Piipponen M, Heino J, Kähäri VM, Nissinen L: Long non-coding RNA PICSAR decreases adhesion and promotes migration of squamous carcinoma cells by downregulating $\alpha 2 \beta 1$ and $\alpha 5 \beta 1$ integrin expression. Biol Open 2018, 7:bio037044

24. Farshchian M, Nissinen L, Grénman R, Kähäri VM: Dasatinib promotes apoptosis of cutaneous squamous carcinoma cells by regulating activation of ERK1/2. Exp Dermatol 2017, 26:89-92 
25. Robinson JT, Thorvaldsdóttir H, Winckler W, Guttman M, Lander ES, Getz G, Mesirov JP: Integrative genomics viewer. Nat Biotechnol 2011, 29:24-26

26. Stokes A, Joutsa J, Ala-Aho R, Pitchers M, Pennington CJ, Martin C, Premachandra DJ, Okada Y, Peltonen J, Grénman R, James HA, Edwards DR, Kähäri VM: Expression profiles and clinical correlations of degradome components in the tumor microenvironment of head and neck squamous cell carcinoma. Clin Cancer Res 2010, 16:2022-2235

27. Anderson CM, Zhang B, Miller M, Butko E, Wu X, Laver T, Kernag C, Kim J, Luo Y, Lamparski H, Park E, Su N, Ma XJ: Fully automated RNAscope in situ hybridization assays for formalin-fixed paraffinembedded cells and tissues. J Cell Biochem 2016, 117:2201-2208

28. Bankhead P, Loughrey MB, Fernández JA, Dombrowski Y, McArt DG, Dunne PD, McQuaid S, Gray RT, Murray LJ, Coleman HG, James JA, Salto-Tellez M, Hamilton PW, QuPath: Open source software for digital pathology image analysis. Sci Rep 2017, 7:16878

29. Katayose D, Wersto R, Cowan KH, Seth P: Effects of a recombinant adenovirus expressing WAF1/Cip1 on cell growth, cell cycle, and apoptosis. Cell Growth Differ 1995, 6:1207-1212

30. Wilkinson GW, Akrigg A: Constitutive and enhanced expression from the CMV major IE promoter in a defective adenovirus vector. Nucleic Acids Res 1992, 20:2233-2239

31. Huber W, Carey VJ, Gentleman R, Anders S, Carlson M, Carvalho BS, Bravo HC, Davis S, Gatto L, Girke T, Gottardo R, Hahne F, Hansen KD, Irizarry RA, Lawrence M, Love MI, MacDonald J, Obenchain V, Oleś AK, Pagès H, Reyes A, Shannon P, Smyth GK, Tenenbaum D, Waldron L, Morgan M: Orchestrating high-throughput genomic analysis with Bioconductor. Nat Methods 2015, 12:115-121

32. Ritchie ME, Phipson B, Wu D, Hu Y, Law CW, Shi W, Smyth GK: Limma powers differential expression analyses for RNA-sequencing and microarray studies. Nucleic Acids Res 2015, 43:e47

33. Fishilevich S, Nudel R, Rappaport N, Hadar R, Plaschkes I, Iny Stein T, Rosen N, Kohn A, Twik M, Safran M, Lancet D, Cohen D: GeneHancer: genome-wide integration of enhancers and target genes in GeneCards. Database (Oxford) 2017, 2017:bax028

34. Euhus DM, Hudd C, LaRegina MC, Johnson FE: Tumor measurement in the nude mouse. J Surg Oncol 1986, 31:229-234

35. Tripathi V, Ellis JD, Shen Z, Song DY, Pan Q, Watt AT, Freier SM, Bennett CF, Sharma A, Bubulya PA, Blencowe BJ, Prasanth SG, Prasanth KV: The nuclear-retained noncoding RNA MALAT1 regulates alternative splicing by modulating SR splicing factor phosphorylation. Mol Cell 2010, 39:925-938

36. Servomaa K, Kiuru A, Grénman R, Pekkola-Heino K, Pulkkinen JO, Rytömaa T: p53 mutations associated with increased sensitivity to ionizing radiation in human head and neck cancer cell lines. Cell Prolif 1996, 29:219-230

37. Boukamp P, Petrussevska RT, Breitkreutz D, Hornung J, Markham A, Fusenig NE: Normal keratinization in a spontaneously immortalized aneuploid human keratinocyte cell line. J Cell Biol 1988, 106:761-771

38. Georgakilas AG, Martin OA, Bonner WM: p21: a two-faced genome guardian. Trends Mol Med 2017, 23:310-319

39. Kretz M, Webster DE, Flockhart RJ, Lee CS, Zehnder A, LopezPajares V, Qu K, Zheng GX, Chow J, Kim GE, Rinn JL, Chang HY, Siprashvili Z, Khavari PA: Suppression of progenitor differentiation requires the long noncoding RNA ANCR. Genes Dev 2012, 26:338-343

40. Kretz M, Siprashvili Z, Chu C, Webster DE, Zehnder A, Qu K, Lee CS, Flockhart RJ, Groff AF, Chow J, Johnston D, Kim GE, Spitale RC, Flynn RA, Zheng GX, Aiyer S, Raj A, Rinn JL, Chang HY, Khavari PA: Control of somatic tissue differentiation by the long non-coding RNA TINCR. Nature 2013, 493:231-235

41. Gupta R, Ahn R, Lai K, Mullins E, Debbaneh M, Dimon M, Arron S, Liao W: Landscape of long noncoding RNAs in psoriatic and healthy skin. J Invest Dermatol 2016, 136:603-609

42. Li J, Long W, Li Q, Zhou Q, Wang Y, Wang H, Zhou B, Li J: Distinct expression profiles of 1 ncRNAs between regressive and mature scars. Cell Physiol Biochem 2015, 35:663-675
43. Kim KH, Kim HJ, Lee TR: Epidermal long non-coding RNAs are regulated by ultraviolet irradiation. Gene 2017, 637:196-202

44. Yo K, Rünger TM: UVA and UVB induce different sets of long noncoding RNAs. J Invest Dermatol 2017, 137:769-772

45. Richtig G, Ehall B, Richtig E, Aigelsreiter A, Gutschner T, Pichler M: Function and clinical implications of long non-coding RNAs in melanoma. Int J Mol Sci 2017, 18:715

46. Zhang Y, Gao L, Ma S, Ma J, Wang Y, Li S, Hu X, Han S, Zhou M, Zhou L, Ding Z: MALAT1-KTN1-EGFR regulatory axis promotes the development of cutaneous squamous cell carcinoma. Cell Death Differ 2019, 26:2061-2073

47. Li F, Liao J, Duan X, He Y, Liao Y: Upregulation of LINC00319 indicates a poor prognosis and promotes cell proliferation and invasion in cutaneous squamous cell carcinoma. J Cell Biochem 2018, 119:10393-10405

48. Lee CS, Mah A, Aros CJ, Lopez-Pajares V, Bhaduri A, Webster DE, Kretz M, Khavari PA: Cancer-associated long noncoding RNA SMRT-2 controls epidermal differentiation. J Invest Dermatol 2018, 138: $1445-1449$

49. Liu H, Li J, Koirala P, Ding X, Chen B, Wang Y, Wang Z, Wang C, Zhang X, Mo YY: Long non-coding RNAs as prognostic markers in human breast cancer. Oncotarget 2016, 7:20584-20596

50. Ye T, Ding W, Wang N, Huang H, Pan Y, Wei A: Long noncoding RNA LINC00346 promotes the malignant phenotypes of bladder cancer. Biochem Biophys Res Commun 2017, 491:79-84

51. Zhang B, Li C, Sun Z: Long non-coding RNA LINC00346, LINC00578, LINC00673, LINC00671, LINC00261, and SNHG9 are novel prognostic markers for pancreatic cancer. Am J Transl Res 2018, 10:2648-2658

52. Wang F, Chen JG, Wang LL, Yan ZZ, Chen SP, Wang XG: Upregulation of LINC00346 inhibits proliferation of non-small cell lung cancer cells through mediating JAK-STAT3 signaling pathway. Eur Rev Med Pharmacol Sci 2017, 21:5135-5142

53. Zhang J, Fan D, Jian Z, Chen GG, Lai PBS: Cancer specific long noncoding RNAs show differential expression patterns and competing endogenous RNA potential in hepatocellular carcinoma. PLoS One 2015, 10:e141042

54. Hafner C, Toll A, Fernández-Casado A, Earl J, Marqués M, Acquadro F, Méndez-Pertuz M, Urioste M, Malats N, Burns JE, Knowles MA, Cigudosa JC, Hartmann A, Vogt T, Landthaler M, Pujol RM, Real FX: Multiple oncogenic mutations and clonal relationship in spatially distinct benign human epidermal tumors. Proc Natl Acad Sci U S A 2010, 107:20780-20785

55. Soussi T, Béroud C: Assessing TP53 status in human tumours to evaluate clinical outcome. Nat Rev Cancer 2001, 1:233-240

56. Sakatani S, Kusakabe H, Kiyokane K, Suzuki K: p53 gene mutations in squamous cell carcinoma occurring in scars: comparison with p53 protein immunoreactivity. Am J Dermatopathol 1998, 20: 463-467

57. Einspahr JG, Alberts DS, Warneke JA, Bozzo P, Basye J, Grogan TM, Nelson MA, Bowden GT: Relationship of p53 mutations to epidermal cell proliferation and apoptosis in human UV-induced skin carcinogenesis. Neoplasia 1999, 1:468-475

58. Bukhari MH, Niazi S, Khaleel ME, Sharif MA, Ghani R, Mehmood MT, Tahseen M, Chaudhry NA, Hasan M: Elevated frequency of 553 genetic mutations and $\mathrm{AgNOR}$ values in squamous cell carcinoma. J Cutan Pathol 2009, 36:220-228

59. Onodera H, Nakamura S, Sugai T: Cell proliferation and $\mathrm{p} 53$ protein expressions in cutaneous epithelial neoplasms. Am J Dermatopathol 1996, 18:580-588

60. Sánchez Y, Segura V, Marín-Béjar O, Athie A, Marchese FP, González J, Bujanda L, Guo S, Matheu A, Huarte M: Genome-wide analysis of the human p53 transcriptional network unveils a lncRNA tumour suppressor signature. Nat Commun 2014, 5:5812

61. Tripathi V, Shen Z, Chakraborty A, Giri S, Freier SM, Wu X, Zhang Y, Gorospe M, Prasanth SG, Lal A, Prasanth KV: Long noncoding RNA MALAT1 controls cell cycle progression by 
regulating the expression of oncogenic transcription factor B-MYB. PLoS Genet 2013, 9:e1003368

62. Zhang A, Zhou N, Huang J, Liu Q, Fukuda K, Ma D, Lu Z, Bai C, Watabe K, Mo YY: The human long non-coding RNA-RoR is a p53 repressor in response to DNA damage. Cell Res 2013, 23:340-350

63. Zhou Y, Zhong Y, Wang Y, Zhang X, Batista DL, Gejman R, Ansell PJ, Zhao J, Weng C, Klibanski A: Activation of p53 by MEG3 non-coding RNA. J Biol Chem 2007, 282:24731-24742

64. Fischer M: Census and evaluation of p53 target genes. Oncogene 2017, 36:3943-3956

65. Sano S, Chan KS, DiGiovanni J: Impact of Stat3 activation upon skin biology: a dichotomy of its role between homeostasis and diseases. J Dermatol Sci 2008, 50:1-14

66. Wang Y, Shen Y, Wang S, Shen Q, Zhou X: The role of STAT3 in leading the crosstalk between human cancers and the immune system. Cancer Lett 2018, 415:117-128

67. Itoh M, Murata T, Suzuki T, Shindoh M, Nakajima K, Imai K, Yoshida K: Requirement of STAT3 activation for maximal collagenase-1 (MMP-1) induction by epidermal growth factor and malignant characteristics in T24 bladder cancer cells. Oncogene 2006, 25:1195-1204

68. Tsareva SA, Moriggl R, Corvinus FM, Wiederanders B, Schütz A, Kovacic B, Friedrich K: Signal transducer and activator of transcription 3 activation promotes invasive growth of colon carcinomas through matrix metalloproteinase induction. Neoplasia 2007, 9: 279-291

69. Airola K, Johansson N, Kariniemi AL, Kähäri VM, SaarialhoKere UK: Human collagenase-3 is expressed in malignant squamous epithelium of the skin. J Invest Dermatol 1997, 199:225-231
70. Johansson N, Airola K, Grénman R, Kariniemi AL, SaarialhoKere U, Kähäri VM: Expression of collagenase-3 (matrix metalloproteinase-13) in squamous cell carcinomas of the head and neck. Am J Pathol 1997, 151:499-508

71. Ala-aho R, Grénman R, Seth P, Kähäri VM: Adenoviral delivery of p53 gene suppresses expression of collagenase-3 (MMP-13) in squamous carcinoma cells. Oncogene 2002, 21:1187-1195

72. Kerkelä E, Ala-aho R, Lohi J, Grénman R, M-Kähäri V, SaarialhoKere U: Differential patterns of stromelysin-2 (MMP-10) and MT1MMP (MMP-14) expression in epithelial skin cancers. Br J Cancer 2001, 84:659-669

73. Cordani M, Pacchiana R, Butera G, D’Orazi G, Scarpa A, Donadelli M: Mutant p53 proteins alter cancer cell secretome and tumour microenvironment: involvement in cancer invasion and metastasis. Cancer Lett 2016, 376:303-309

74. Schulz-Heddergott R, Stark N, Edmunds SJ, Li J, Conradi LC, Bohnenberger H, Ceteci F, Greten FR, Dobbelstein M, Moll UM: Therapeutic ablation of gain-of-function mutant p53 in colorectal cancer inhibits Stat3-mediated tumor growth and invasion. Cancer Cell 2018, 34:298-314.e7

75. Kessenbrock K, Plaks V, Werb Z: Matrix metalloproteinases: regulators of the tumor microenvironment. Cell 2010, 141:52-67

76. Karppinen SM, Honkanen HK, Heljasvaara R, Riihilä P, AutioHarmainen H, Sormunen R, Harjunen V, Väisänen MR, Väisänen T, Hurskainen T, Tasanen K, Kähäri VM, Pihlajaniemi T: Collagens XV and XVIII show different expression and localisation in cutaneous squamous cell carcinoma: type $\mathrm{XV}$ appears in tumor stroma, while XVIII becomes upregulated in tumor cells and lost from microvessels. Exp Dermatol 2016, 25:348-354 